\title{
Vertically-resolved particle size distribution within and above the mixing layer over the Milan metropolitan area
}

\author{
L. Ferrero ${ }^{1}$, M. G. Perrone ${ }^{1}$, S. Petraccone ${ }^{1}$, G. Sangiorgi ${ }^{1}$, B. S. Ferrini ${ }^{1}$, C. Lo Porto ${ }^{1}$, Z. Lazzati $^{1}$, D. Cocchi ${ }^{2}$, \\ F. Bruno ${ }^{2}$, F. Greco ${ }^{2}$, A. Riccio ${ }^{3}$, and E. Bolzacchini ${ }^{1}$ \\ ${ }^{1}$ POLARIS research centre, Department of Environmental Sciences, University of Milano-Bicocca, Piazza della Scienza 1, \\ 20126, Milano, Italy \\ ${ }^{2}$ Department of Statistics "P. Fortunati”, University of Bologna, Via delle Belle Arti 41, 40126, Bologna, Italy \\ ${ }^{3}$ Department of Applied Science, University "Parthenope", Centro Direzionale, Isola C4, 80143, Napoli, Italy
}

Received: 30 March 2009 - Published in Atmos. Chem. Phys. Discuss.: 5 August 2009

Revised: 13 April 2010 - Accepted: 15 April 2010 - Published: 27 April 2010

\begin{abstract}
Vertical aerosol profiles were directly measured over the city of Milan during three years (2005-2008) of field campaigns. An optical particle counter, a portable meteorological station and a miniaturized cascade impactor were deployed on a tethered balloon. More than 300 vertical profiles were measured, both in winter and summer, mainly in conditions of clear, dry skies.

The mixing height was determined from the observed vertical aerosol concentration gradient, and from potential temperature and relative humidity profiles. Results show that inter-consistent mixing heights can be retrieved highlighting good correlations between particle dispersion in the atmosphere and meteorological parameters. Mixing height growth speed was calculated for both winter and summer showing the low potential atmospheric dispersion in winter.

Aerosol number size distribution and chemical composition profiles allowed us to investigate particle behaviour along height. Aerosol measurements showed changes in size distribution according to mixing height. Coarse particle profiles $\left(d_{p}>1.6 \mu \mathrm{m}\right)$ were distributed differently than the fine ones $\left(d_{p}<1.6 \mu \mathrm{m}\right)$ were, at different heights of the mixing layer. The sedimentation process influenced the coarse particle profiles, and led to a reduction in mean particle diameter for those particles observed by comparing data above the mixing height with ground data $(-14.9 \pm 0.6 \%$ in winter and $-10.7 \pm 1.0 \%$ in summer). Conversely, the mean particle diameter of fine particles increased above the mixing height under stable atmospheric conditions; the average in-
\end{abstract}

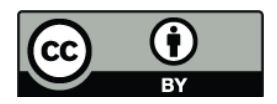

Correspondence to: L. Ferrero

(luca.ferrero@unimib.it) crease, observed by comparing data above the mixing height with ground data, was $+2.1 \pm 0.1 \%$ in winter and $+3.9 \pm 0.3 \%$ in summer. A hierarchical statistical model was created to describe the changes in the size distribution of fine particles along height. The proposed model can be used to estimate the typical vertical profile characterising launches within prespecified groups starting from: aerosol size and meteorological conditions measured at ground-level, and a mixing height estimation. The average increase of fine particle diameter, estimated on the basis of the model, was $+1.9 \pm 0.5 \%$ in winter and $+6.1 \pm 1.2 \%$ in summer, in keeping with experimental findings.

\section{Introduction}

Atmospheric particulate matter (PM) is a crucial factor in environmental pollution, health hazards and climate change. Meteorological conditions, and in particular mixing layer (ML) height, influence the PM exposure pattern providing the available volume for the dispersion of aerosols and gases (Fischer et al., 2006; Seibert et al., 2000). Aerosols also influence the climatic system, as they tend to counter the global-warming effects of greenhouse gases, by cooling the earth-atmosphere system (IPCC, 2007; Koren et al., 2004; Kaufman et al., 2002). The number size distribution and chemical composition of the particles in the atmosphere influence the optical properties of aerosol and their ability to act as cloud condensation nuclei (Kaufman et al., 2002; Penner et al., 2001; Hinds, 1999; Seinfeld, 1998).

The link between the particles' chemical-physical properties and their optical ones has led in recent years to the

Published by Copernicus Publications on behalf of the European Geosciences Union. 
use of satellite images to spatialize the PM exposure pattern (Shaap et al., 2009; Di Nicolantonio et al., 2009; EngelCox et al., 2006; Liu et al., 2005, 2007; Sarigiannis et al., 2004). However, in order to quantitatively relate aerosol optical depth (AOD) to ground levels of PM, the effective scale height $\left(H_{\text {eff }}\right)$ of the aerosol has to be estimated (Wang et al., 2003; Kaufman and Fraser, 1983). Studies tend to use mixing height, predicted by different models, instead of $H_{\text {eff }}$ (Di Nicolantonio et al., 2007, 2009; Levy et al., 2007; Liu et al., 2005; Sarigiannis et al., 2004). This simplification of the problem can be achieved by assuming a homogeneous mixing of particles within the mixing layer, and the presence of low aerosol concentrations above it.

As Campanelli et al. (2003) and Corrigan et al. (2008) have pointed out, the remote sensing approach (i.e. satellite and sun-photometers) requires different kinds of assumptions to be made regarding physical, optical and chemical aerosol parameters, in addition to homogeneity which may not provide valid results (Wiegner et al., 2006; Levy et al., 2004; Dubovik et al., 2000, Doherty et al., 1999).

However, it has been shown that aerosols can vary greatly in concentration, size and composition through the atmosphere, and thus also in terms of their effects on incident radiation (Campanelli et al., 2003).

Studies have highlighted the opposing behaviour of vertical aerosol properties in the lower troposphere. For example, Campanelli et al. (2003) reported that boundary layer thickness had no influence on changes in aerosol volume size distribution along height; whereas Hayasaka et al. (1998) demonstrated a connection between the columnar aerosol volume size distribution and details of vertical profiles.

Thus, climatic studies and the estimation of ground PM concentrations from satellites, require a 3-D knowledge of aerosol properties, especially along the whole atmospheric column (Wang et al., 2003; Kaufman and Fraser, 1983).

Vertical aerosol profiles can be obtained using both direct techniques, such as tethered balloons (McKendry et al., 2004; Stratmann et al. 2003; Maletto et al., 2003) and aircraft (Taubman et al., 2006; Wiegner et al., 2006), and indirect techniques such as lidars (Kim et al., 2007; Amiridis at al., 2007; Eresmaa et al., 2006). Of these, only direct techniques enable us to measure the physicochemical properties of aerosols (number concentration, size distribution, chemical composition) and the effect of atmospheric turbulence on aerosol properties within and above the mixing layer (Seibert et al., 2000).

Until now, direct long-term measurements of vertical particle properties have been scarce (Penner et al., 2001); those that do exist are limited to just a few locations (Gobbi et al., 2004) and were mainly carried out during short-peculiar sampling campaigns (Laakso et al., 2007; Wiegner et al., 2006; McKendry et al., 2004; Maletto et al., 2003; Stratmann et al., 2003).

As far as we know, this kind of measurement has not yet been the object of statistical modelling in the lower tropo- sphere. A Bayesian algorithm was recently applied to stratospheric aerosol extinction data to retrieve size distribution parameters at high altitude (Wurl et al., 2009).

Following this approach, vertical aerosol profiles were measured in Milan, within the framework of the Italian QUITSAT project (Air quality in the Po Valley by integrated measurements from Earth, satellites and chemical-transport modelling; www.quitsat.it), over the course of three years of field campaigns. Collected data were analysed using a statistical modelling approach, in order to describe characteristic particle size changes along height, within and above the mixing layer. The result was a probabilistic model capable of predicting particle properties along height based on ground measurements (aerosol size distribution and meteorological parameters) and mixing height. A statistical approach has the advantage of not requiring information about nucleation, coagulation, condensation and evaporation processes (Laakso et al., 2007; Kulmala et al., 2004; Stratmann et al., 2003) in order to correctly predict aerosol size distribution along height; transport events were also included in a general law valid under specific meteorological conditions.

\section{Site, instrumentation and statistical approach}

Vertical profiles of atmospheric aerosol were performed at the urban site of Torre Sarca in Milan $\left(45^{\circ} 31^{\prime} 194^{\prime \prime} \mathrm{N}\right.$, $9^{\circ} 12^{\prime} 46^{\prime \prime} \mathrm{E}$ - University of Milano-Bicocca). The site is located on the northern side of Milan, in the midst of an extensive conurbation that is the most industrialized and heavilypopulated area in the Po Valley. Wind is scarce in the Po Valley, and stagnant conditions often occur causing a marked seasonally influenced PM trend (Rodriguez et al., 2007; Ferrero et al., 2007; Vecchi et al., 2004).

\subsection{Atmospheric aerosol and meteorological profiles}

Vertical profiles of atmospheric aerosol were performed using a helium filled tethered balloon $\left(\varnothing=4 \mathrm{~m}, 33.5 \mathrm{~m}^{3}\right)$ equipped with an optical particle counter (OPC), a miniaturized cascade impactor and a portable meteorological station; they were deployed on a platform at a distance of $5 \mathrm{~m}$ from the balloon (Fig. 1). An electric winch allowed us to control the ascent and descent rate of the balloon to a precision of $0.1 \mathrm{~m} / \mathrm{min}$; a fixed value of $30.0 \pm 0.1 \mathrm{~m} / \mathrm{min}$ was used, giving a high spatial resolution of particle measurements $(3.0 \mathrm{~m}$ of resolution for each 6-s OPC measurement) with a reasonable time of flight ( $10 \mathrm{~min}$ to reach $300 \mathrm{~m}$ a.g.l.). The maximum height reached by each balloon launch depended on atmospheric conditions; for most of the profiles this height ranged from 300 to $600 \mathrm{~m}$ a.g.l.

We used the OPC GRIMM 1.108 "Dustcheck" which allowed us to measure the particle number size distribution in 15 classes from $0.3 \mu \mathrm{m}$ to up to $20 \mu \mathrm{m}$. The particle concentrations (number and volume) reported in this study only 

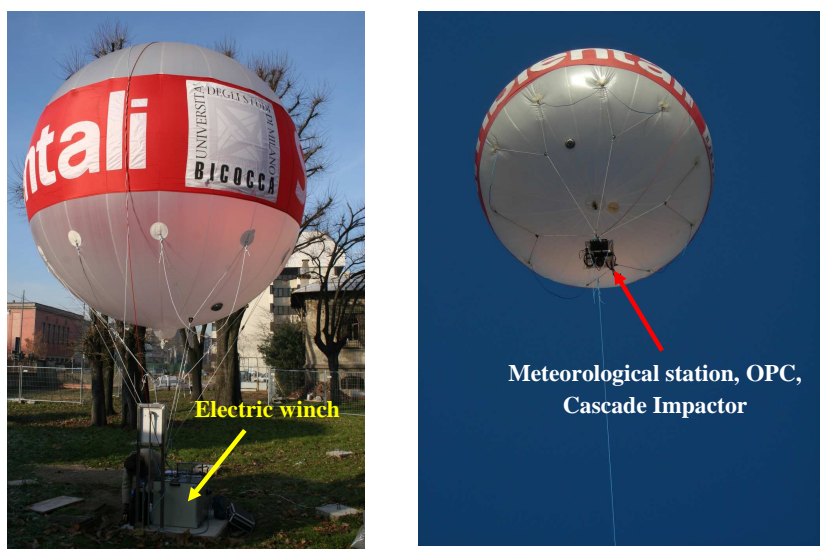

Fig. 1. The tethered balloon and the electric winch at the sampling site, and the balloon during a flight with its payload.

refer to the size range measured by the OPC. The instrument was set to perform one measurement every $6 \mathrm{~s}$ to reach the highest spatial resolution during the balloon's flight. The OPC is suitable for measuring vertical profiles thanks to its light weight $(2.5 \mathrm{~kg})$, small size $\left(24 \times 12 \times 6 \mathrm{~cm}^{3}\right)$, and considerable battery duration $(8 \mathrm{~h})$; this experimental design had been used successfully in other studies (Wiegner et al., 2006; McKendry et al., 2004; Maletto et al., 2003).

The OPCs may be sensitive to conditions of high relative humidity which may influence particle growth. In order to avoid any artefact in size distribution determination, only vertical profiles carried out in clear and dry sky conditions $(\mathrm{RH}<65 \%)$ were considered (Sjogren et al., 2008; Weingartner et al., 1997).

Meteorological conditions along height were measured, at the same time as particle counting and sizing, using a portable meteorological station (BABUC-ABC LSILastem); pressure, temperature and relative humidity were measured with the same time resolution as particle counting. These data were then employed to control the relative humidity (RH) of the atmosphere, allowing us to consider only artefact-free measurements performed by the OPC. Furthermore, humidity usually decreases with height (Baars et al., 2008; Palchetti et al., 2008; Velasco et al., 2008; Laakso et al., 2007; Stratmann et al., 2003), and during balloon launches the mixing height was characterized by a sharp decrease in the RH content. The mean RH decrease across the ML was $8.5 \pm 0.8 \%$.

The availability of vertical profiles of particle number concentration, temperature and relative humidity enabled us to directly infer a mixing height from each of the measured parameters using a gradient method (Ferrero et al., 2007; Kim et al., 2007; Matzuki et al., 2005; McKendry et al., 2004; Maletto et al, 2003; Seibert et al., 2000; Menut et al., 1999). Radiosounding data (potential temperature and relative humidity), measured on the same days of vertical pro- files, from Milano-Linate airport $(9 \mathrm{~km}$ far from the Torre Sarca site on the edge of Milan; http://weather.uwyo.edu/ upperair/sounding.html), were also used to estimate a mixing height. All of these mixing heights are compared with one another in the result and discussion section of this study.

\subsubsection{PM collection and chemical characterization}

During wintertime balloon flights, PM samples were collected using a portable cascade impactor (Sioutas SKC; five stages: $>2.5 \mu \mathrm{m}, 1.0-2.5 \mu \mathrm{m}, 0.5-1.0 \mu \mathrm{m}, 0.25-0.5 \mu \mathrm{m}$, $<0.25 \mu \mathrm{m})$ at different altitudes along the vertical profiles. Teflon filters (Ø 25 and $37 \mathrm{~mm}$, SKC) were used for PM collection, and a stable sampling flow rate of $9 \mathrm{~L} / \mathrm{min}$ was guaranteed by a light-weight $(1 \mathrm{~kg}$ ) battery-supplied pump (Leland Legacy pump, SKC). An internal flow sensor (Isothermal flow controller for air sampler, US Patent No. 5892160) measured flow directly, and acted to maintain the set flow. Set flow is achieved immediately at start-up, and is automatically maintained by built-in sensors that compensate for differences in temperature and atmospheric pressure during sampling.

PM samples were analyzed by means of ion chromatography after $20 \mathrm{~min}$ of extraction in ultrapure (MilliQ) water by ultrasonic bath (SOLTEC SONICA®) (Ferrero et al., 2008). Inorganic anions and cations were jointly analyzed by a Dionex ICS-90 and an ICS-2000 coupled system equipped with: Dionex IonPac ${ }^{\circledR}$ AG14A-5 $\mu \mathrm{m}$ Guard $(3 \times 30 \mathrm{~mm})$, IonPac ${ }^{\circledR}$ AS14A-5 $\mu$ m analytical column $(3 \times 150 \mathrm{~mm})$, AMMS III $2 \mathrm{~mm}$ MicroMembrane Suppressor for anions; IonPac ${ }^{\circledR}$ CG12A-5 $\mu \mathrm{m}$ Guard $(3 \times 30 \mathrm{~mm})$, IonPac ${ }^{\circledR}$ CS12A- $5 \mu \mathrm{m}$ analytical column $(3 \times 150 \mathrm{~mm})$, CMMS III $2 \mathrm{~mm}$ MicroMembrane Suppressor for cations. Eluent and regenerant for anions were $\mathrm{Na}_{2} \mathrm{CO}_{3} / \mathrm{NaHCO}_{3}$ $8.0 \mathrm{mM} / 1.0 \mathrm{mM}$ and $\mathrm{H}_{2} \mathrm{SO}_{4} 0.05 \mathrm{M}$ solutions; for cations they were MSA $20 \mathrm{mM}$ and TBAOH $0.1 \mathrm{M}$ (Perrone et al., 2010). Samples were collected at ground level, and in and above the mixing layer, for one hour. Due to the broad range in size of each cascade impactor stage, no significant changes in ion size distribution were detected along the vertical profiles. This is the reason why we have reported the vertical changes in their total atmospheric concentrations in this present study.

At ground level, $\mathrm{PM}_{1}$ and $\mathrm{PM}_{2.5}$ were constantly monitored (in the case of $\mathrm{PM}_{2.5}$, using a CEN equivalent sampler in compliance with EN-14907). The FAI-Hydra dual channel low-volume sampler was used with PTFE filters $(\varnothing=47 \mathrm{~mm})$ and an EU sampling inlet $\left(2.3 \mathrm{~m}^{3} / \mathrm{h}\right)$.

\subsection{Statistical data analysis and modelling}

Vertical aerosol profiles are characterised by a high degree of heterogeneity in the physicochemical processes that determine their size properties. A hierarchical Bayesian statistical model is a good tools for managing size distribution 

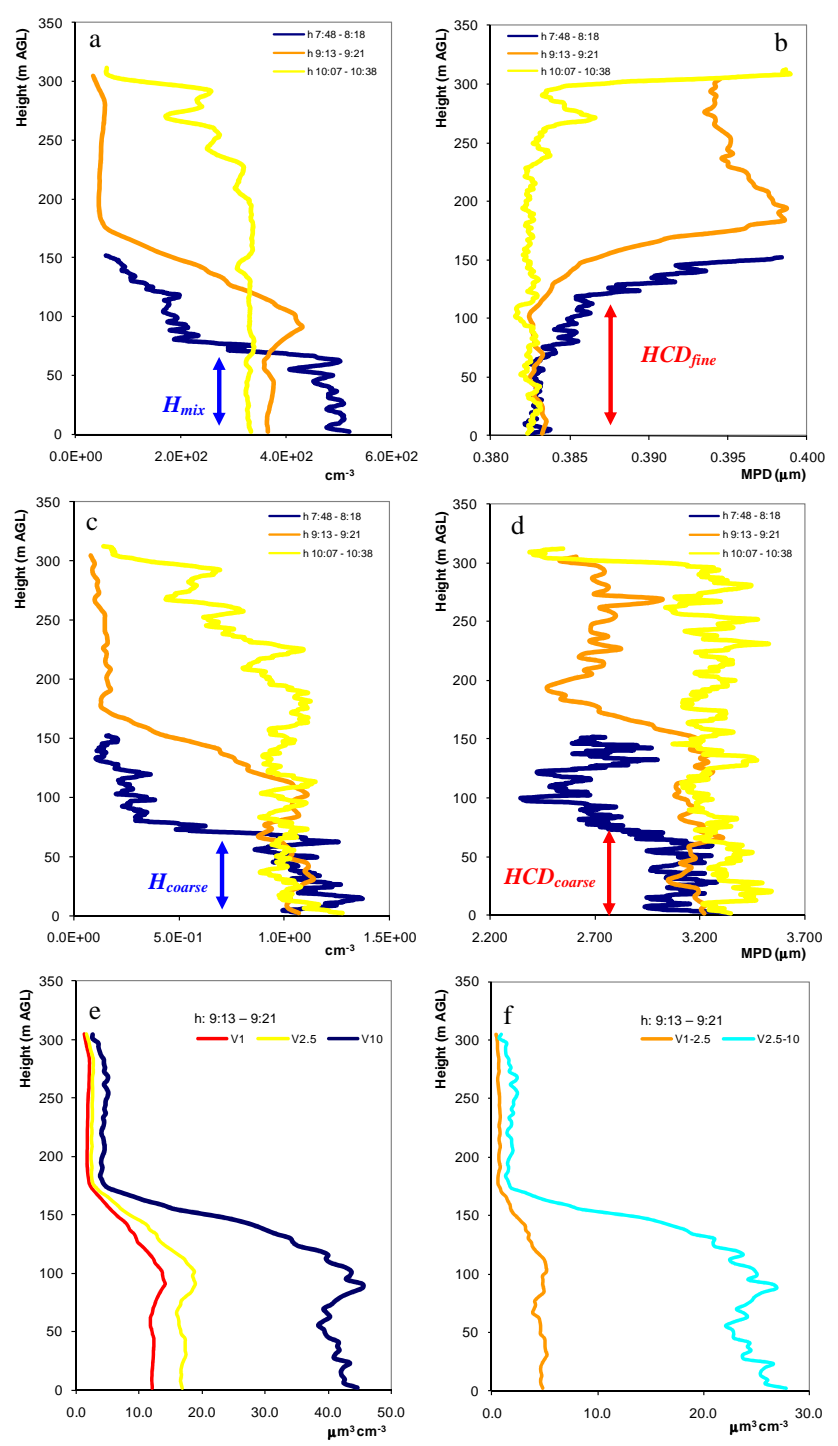

Fig. 2. Selected profiles of particle number concentration, mean particle diameter (MPD) and volume concentration over Torre Sarca on $20^{\text {th }}$ December 2005. Particle number concentration profiles are plotted for fine particles $\left(d_{p}<1.6 \mu \mathrm{m}\right)$ and coarse particles $\left(d_{p}>1.6 \mu \mathrm{m}\right)$ respectively in panels (a) and (c); mean particle diameter (MPD) behaviour along height is plotted for fine and coarse particles respectively in panels (b) and (d). $H_{\text {mix }}$ and $H_{\text {coarse }}$ refer to the heights calculated from the observed vertical concentration gradient for fine and coarse particles of the two-size fraction, respectively. $\mathrm{HCD}_{\text {fine }}$ and $\mathrm{HCD}_{\text {coarse }}$ refer to the heights calculated from the observed vertical MPD gradient for fine and coarse particles respectively. Finally, the profiles of volume concentration $V_{1}, V_{2.5}$ and $V_{10}$ (respectively with $d_{p}$ less than $1 \mu \mathrm{m}, 2.5 \mu \mathrm{m}$ and $10 \mu \mathrm{m}$ ), and their in-between $V_{1-2.5}$ and $V_{2.5-10}$, are plotted, respectively, in panels (e) and (f); they refer to the "h: 9:13-9:21" balloon flight of the 20th December 2005. variations along height, hence this kind of model was developed here. Parameter estimation was performed by means of simulation procedures via a Monte Carlo Markov Chain (MCMC) algorithm implemented in the OpenBugs Software for Windows (Spiegelhalter et al., 1998).

The Bayesian framework is particularly suitable for managing this kind of models (Wikle et al., 1998). The hierarchical model presents three levels: the first constructs the data likelihood that describes the data generating process. The second is devoted to launch-specific modelling. At the third level, the model describes the typical behaviour of a vertical profile. Each level is characterized by specific parameters. Parameter estimation is the way to obtain modelled vertical profiles, which are the main results of our approach. The Bayesian formulation is completed by specifying prior distributions on the parameters themselves (hyperpriors on hyperparameters).

\section{Results and discussion}

Vertical profile measurements were performed over the city of Milan between 2005 and 2008, by collecting more than 300 profiles in the characteristically stagnant conditions of the Po Valley. Among these only 214 profiles showed the presence of a mixing height. These provided a complete behaviour profile of aerosol properties in the lower troposphere during winter (the months of D, J and F; 142 profiles) and summer (the months of $\mathrm{J}, \mathrm{J}$ and $\mathrm{A} ; 72$ profiles). Average ground wind speed in Milan during these campaigns was very low: $0.84 \pm 0.03 \mathrm{~m} / \mathrm{s}$ in winter and $1.61 \pm 0.04 \mathrm{~m} / \mathrm{s}$ in summer. Measurements were generally performed in the morning, from sunrise to 13:00 UTC (83\% of measured profiles); this timing was designed to best describe the particle properties along height during the MODIS (Moderate Resolution Imaging Spectroradiometer) Terra and Aqua overflight of the Po Valley. The remaining measurements $(17 \%)$ were taken in the afternoon up until sunset. Figure 2a, c, e, f offers characteristic examples from the whole vertical profile dataset, as a case study.

\subsection{Mixing height determination}

Particle accumulation in the ML gave rise to a marked concentration gradient in correspondence with the mixing height $\left(H_{\text {mix }}\right)$. An example of this is clearly visible in Fig. 2. From the ground to $H_{\text {mix }}$ the number-concentration was quite stable. There are a considerable number of definitions of $H_{\text {mix }}$ in the literature (either theoretical or operational), the choice depending mainly on data availability (Seibert et al., 2000).

Atmospheric particles act as a tracer of the atmospheric dispersion state; this information contains and integrates the effects of physical atmospheric forces (both thermal and mechanical) on particle dispersion. In the present study, particle number-concentration profiles were investigated using a 

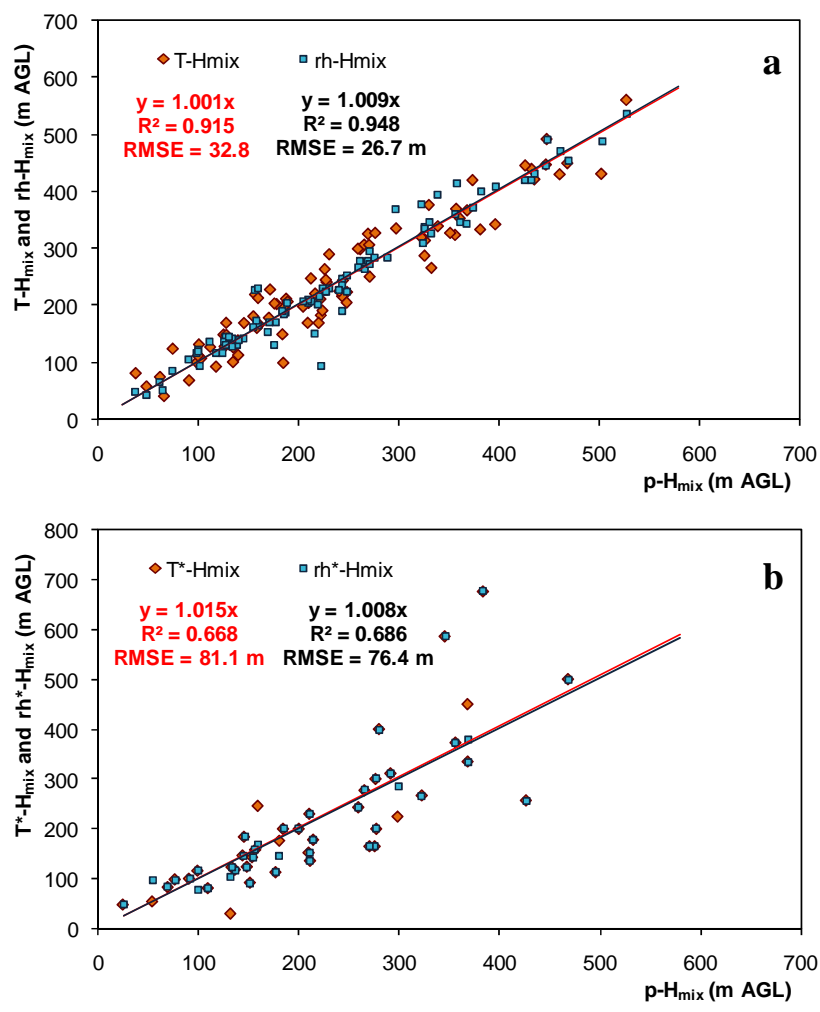

Fig. 3. (a) the correlation between the particle-derived mixing height $\left(p-H_{\text {mix }}\right)$, and the temperature- and relative humidityderived mixing heights (respectively $T-H_{\mathrm{mix}}$ and $r h-H_{\mathrm{mix}}$ ) estimated from vertical profile measurements; (b) the correlation between the particle-derived mixing height $\left(p-H_{\text {mix }}\right)$ estimated from vertical profile measurements. and the temperature- and relative humidity-derived mixing heights (respectively $T^{*}-H_{\text {mix }}$ and $r h^{*}-H_{\text {mix }}$ ) estimated from radiosoundings at Milano-Linate airport.

gradient method to define $H_{\text {mix }}$ (Ferrero et al., 2007; Kim et al., 2007; Matzuki et al., 2005; McKendry et al., 2004; Maletto et al, 2003; Seibert et al., 2000; Menut et al., 1999).

Since section 3.3 proposes a probabilistic model, capable of predicting particle size along height, starting from aerosol size at ground-level, meteorological parameters and mixing height, the reliability of particle-derived $H_{\mathrm{mix}}$ has to be assessed.

For this reason, particle-derived $H_{\text {mix }}$ (indicated here as $\left.p-H_{\text {mix }}\right)$ was compared with a mixing height estimation derived at the same time from temperature $\left(T-H_{\text {mix }}\right)$ and relative humidity $\left(r h-H_{\text {mix }}\right)$ profiles measured using the meterological station deployed on the balloon; $T-H_{\operatorname{mix}}$ and $r h-H_{\text {mix }}$ were calculated by means of the gradient method as reported also in the work of Kim et al. (2007). Figure 3a compares $p-H_{\text {mix }}, T-H_{\text {mix }}$ and $r h-H_{\text {mix }}$. Temperature and relative humidity mixing heights were also estimated from radiosoundings performed at Milano-Linate airport (here indicated as: $T^{*}-H_{\text {mix }}$ and $\left.r h^{*}-H_{\text {mix }}\right)$ and compared to the closest observation of $p-H_{\text {mix }}$ (Fig. 3b).
The $p-H_{\text {mix }}, T-H_{\text {mix }}$ and $r h-H_{\text {mix }}$ estimated from balloon profiles coincided to a considerable extent (Fig. 3a), and a root mean squared error (RMSE) of $32.8 \mathrm{~m}$ was found between $p-H_{\text {mix }}$ and $T-H_{\text {mix }}$, while a RMSE of $26.7 \mathrm{~m}$ was calculated between $p-H_{\text {mix }}$ and $r h-H_{\text {mix }}$. Mixing heights estimated from radiosoundings of Milano-Linate airport $\left(T^{*}-H_{\text {mix }}\right.$ and $\left.r h^{*}-H_{\text {mix }}\right)$ showed a lower degree of correlation with $p-H_{\mathrm{mix}}$ (RMSE respectively of $81.1 \mathrm{~m}$ and $76.4 \mathrm{~m}$ ). This is understandable given that radiosoundings are generally collected at 06:00 and 12:00 UTC only, and even if they are related to the closest balloon's vertical profile, their timing does not coincide with that of the balloon measurements (Ferrero et al., 2007); moreover, available radiosounding data are characterised by low vertical resolution, compared to vertical profiles (about $3.0 \mathrm{~m}$ ), which leads to the reduced accuracy of mixing height estimation.

However, both linear correlations of $p-H_{\text {mix }}$ with $T-$ $H_{\text {mix }}$ and $r h-H_{\text {mix }}$, and with $T^{*}-H_{\text {mix }}$ and $r h^{*}-H_{\text {mix }}$, displayed slopes very close to one, revealing the link between meteorological parameters and aerosol dispersion.

Finally, as reported in Angelini et al. (2009), balloon derived $p-H_{\operatorname{mix}}$ was also successfully compared with an estimation of mixing height performed using an automated lidar ceilometer (Vaisala LD40, $\lambda=855 \mathrm{~nm}$ ) installed at the Torre Sarca site at the same time as the balloon launching. All of these results underline the accuracy of $p-H_{\text {mix }}$ in estimating mixing height. This the reason why hereinafter we are going to refer to the mixing height as that derived from particle concentration gradient, indicated simply as $H_{\text {mix }}$.

$H_{\text {mix }}$ shows a clear temporal development (Fig. 2a) which was seasonally averaged and plotted in Fig. $4 a$ and b. Figure $4 \mathrm{a}$ shows the whole diurnal cycle of $H_{\text {mix }}$ in winter, when vertical profiles measurements were able to establish the $H_{\text {mix }}$ throughout the day. In the winter, a slight evolution in mixing height was observed, underling the stagnant conditions present above Milan (Ferrero et al., 2007). On the contrary, greater convection in the early morning is clearly visible in summer (Fig. 4b).

$H_{\text {mix }}$ growth speed was calculated for winter and summer (Fig. 4a, b). On average, growth speed in winter reached values of $150-200 \mathrm{~m} / \mathrm{h}\left(95^{\circ}\right.$ percentile $\left.=282 \mathrm{~m} / \mathrm{h}\right)$ at noon; in summer, on the other hand, already early in the morning (08:00 UTC), $H_{\text {mix }}$ growth speed increased quickly to $300 \mathrm{~m} / \mathrm{h}\left(95^{\circ}\right.$ percentile $\left.=338 \mathrm{~m} / \mathrm{h}\right)$. Calculated growth speed values are comparable with those reported by Baars et al. (2008).

\subsection{Number size distribution and chemical composition along height}

The number size distributions measured at ground level and over the ML in winter and summer (Fig. 5a and b) showed a local minimum in the $1.0-1.6 \mu \mathrm{m}$ size class of the OPC; hence we discuss the coarse fraction behaviour along height 
Table 1. Aerosol volume concentration (mean and mean standard deviation $\sigma_{m}$ ) at ground-level (G), above the mixing layer (AML) and the ratio between the two. Data were collected in winter (DJF months; $N$ profiles $=142$ ) and in summer (JJA months; $N$ profiles $=72$ ). $V_{1}$, $V_{2.5}, V_{10}$ and their in-between $V_{1-2.5}$ and $V_{2.5-10}$ are calculated considering particle smaller than $1 \mu \mathrm{m}, 2.5 \mu \mathrm{m}, 10 \mu \mathrm{m}$ and in the ranges $1-2.5 \mu \mathrm{m}$ and $2.5-10 \mu \mathrm{m}$. Concentrations measured above the mixing layer are normalized to ground pressure and temperature.

\begin{tabular}{|c|c|c|c|c|c|c|c|c|c|c|c|c|c|c|c|}
\hline \multirow[t]{2}{*}{$\begin{array}{l}\text { Volume conc. } \\
\left(\mu \mathrm{m}^{3} \mathrm{~cm}^{-3}\right)\end{array}$} & \multicolumn{5}{|c|}{ Ground-level (G) } & \multicolumn{5}{|c|}{$\begin{array}{l}\text { Above the mixing } \\
\text { layer (AML) }\end{array}$} & \multicolumn{5}{|c|}{ AML/G (\%) } \\
\hline & $V_{1}$ & $V_{2.5}$ & $V_{10}$ & $V_{1-2.5}$ & $V_{2.5-10}$ & $V_{1}$ & $V_{2.5}$ & $V_{10}$ & $V_{1-2.5}$ & $V_{2.5-10}$ & $V_{1}$ & $V_{2.5}$ & $V_{10}$ & $V_{1-2.5}$ & $V_{2.5-10}$ \\
\hline Winter mean & 20.0 & 27.7 & 43.9 & 7.7 & 16.2 & 5.9 & 7.4 & 8.7 & 1.5 & 1.3 & 30.4 & 27.1 & 20.3 & 20.8 & 8.7 \\
\hline Winter $\sigma_{m}$ & 0.8 & 1.0 & 1.6 & 0.3 & 0.9 & 0.4 & 0.5 & 0.6 & 0.1 & 0.1 & 1.9 & 1.6 & 1.2 & 1.2 & 0.8 \\
\hline Summer mean & 3.5 & 11.4 & 26.3 & 7.8 & 14.9 & 1.3 & 5.5 & 10.4 & 4.1 & 4.9 & 38.7 & 42.4 & 36.6 & 43.6 & 33.2 \\
\hline Summer $\sigma_{m}$ & 0.2 & 0.7 & 1.6 & 0.6 & 1.0 & 0.1 & 0.6 & 1.1 & 0.5 & 0.6 & 1.9 & 2.9 & 3.3 & 3.5 & 4.2 \\
\hline
\end{tabular}
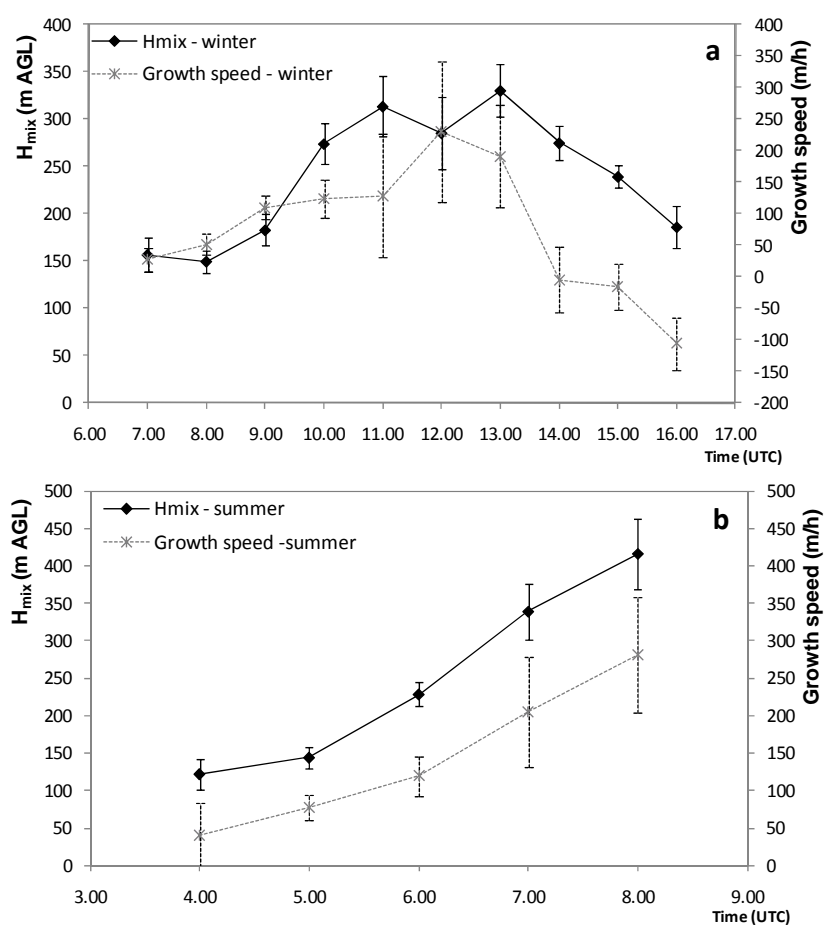

Fig. 4. $H_{\text {mix }}(\mathrm{m})$ and $H_{\text {mix }}$ growth speed $(\mathrm{m} / \mathrm{h})$ hourly averaged values for: (a) winter (DJF months; $\mathrm{N}$ profiles $=142$ ), (b) summer (JJA months; N profiles $=72$ ).

$\left(d_{p}>1.6 \mu \mathrm{m}\right.$; Sect. 3.2.2) separately from the fine fraction behaviour $\left(d_{p}<1.6 \mu \mathrm{m}\right.$; Sects. 3.2.3 and 3.3).

This section examines the relationship between $H_{\text {mix }}$ and aerosol property changes. Number size distribution and chemical composition data, collected above the mixing layer, are compared with those collected near ground-level inside that layer. This is investigated both in winter and summer, at a time of stable conditions and transport events.
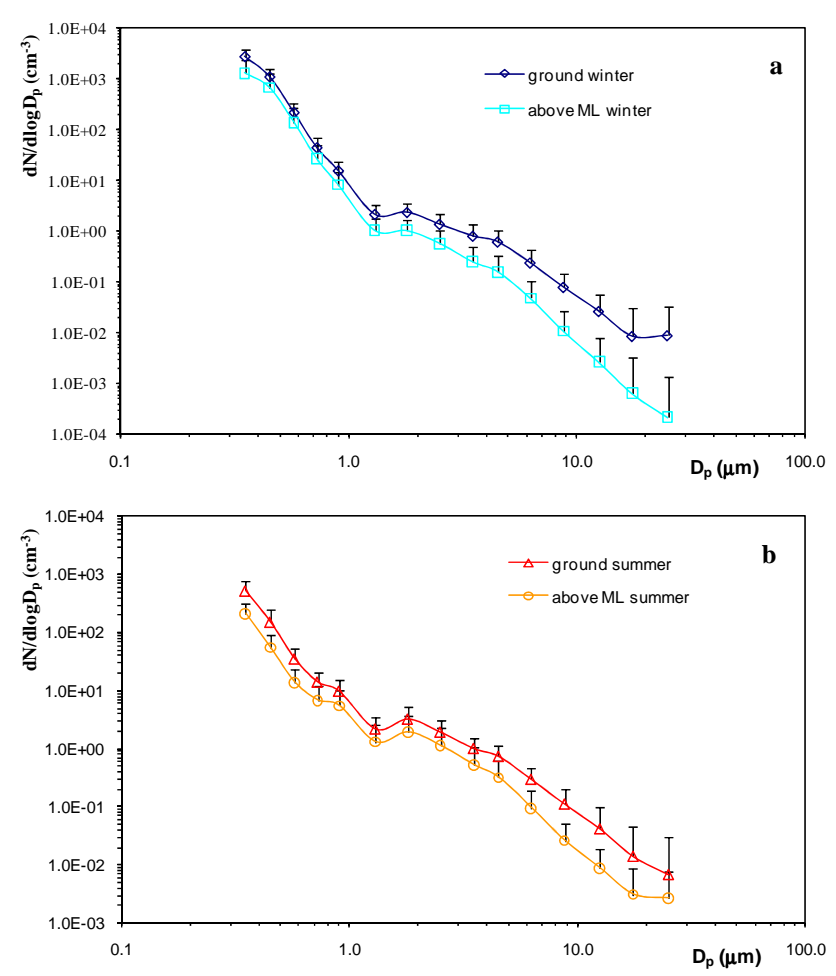

Fig. 5. Number-size distribution of aerosol at ground-level and above the ML both in winter (a) (DJF months; N profiles =142) and summer (b) (JJA months; $\mathrm{N}$ profiles $=72$ ).

\subsubsection{Number and volume concentration above the mixing height}

The power of the mixing layer to trap both primary and secondary particles is shown by those profiles reported in Fig. 2a, c, e and f. This influences the ratio between particle concentration (number and volume) measured above the mixing layer to that measured at ground level. 


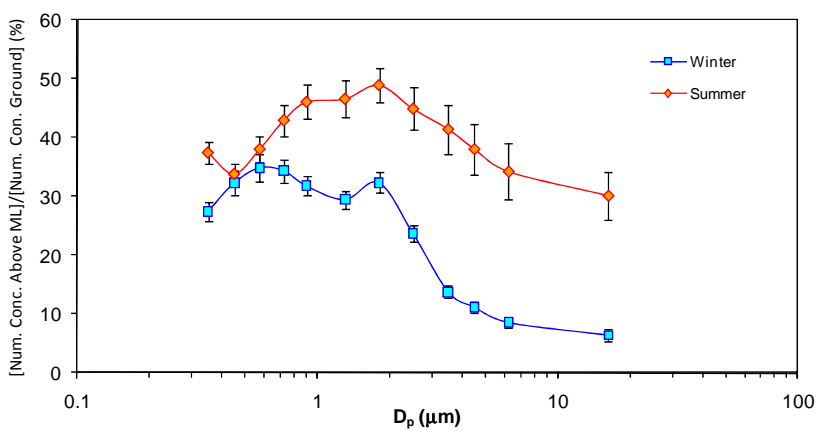

Fig. 6. Percentage of the number-concentration measured above the ML, over that measured at ground-level, as a function of aerosol size. Data were collected in the winter (DJF months; N profiles $=142$ ) and in the summer (JJA months; N profiles $=72$ ).

On average, the particle number concentrations found above the ML (normalized at ground temperature and pressure) were $161 \pm 11 \mathrm{~cm}^{-3}$ in winter and $35 \pm 2 \mathrm{~cm}^{-3}$ in summer; these values represent $29 \pm 2 \%$ and $37 \pm 2 \%$ of the total particle number concentration measured at ground level $\left(589 \pm 23 \mathrm{~cm}^{-3}\right.$ in winter and $98 \pm 6 \mathrm{~cm}^{-3}$ in summer).

Similar results were obtained by calculating the particle volume concentration $V_{1}, V_{2.5}$ and $V_{10}$ (respectively with $d_{p}$ less than $1 \mu \mathrm{m}, 2.5 \mu \mathrm{m}$ and $10 \mu \mathrm{m}$ ) along height, and their in-between $V_{1-2.5}$ and $V_{2.5-10}$ (Fig. 2e, f); their behaviour represents that of $\mathrm{PM}_{1}, \mathrm{PM}_{2.5}$ and $\mathrm{PM}_{10}$ (and of $\mathrm{PM}_{1-2.5}$ and $\mathrm{PM}_{2.5-10}$ ) without considering particle density. Table 1 reports these values at ground-level, above the ML, and their respective ratios.

Particle number and volume concentrations are not negligible above the ML. These results evidenced that an innovative approach in retrieving PM from satellites has to account for their contribution to the optical signal over the ML, a key procedure in areas characterized by stagnant conditions.

Many factors may influence particle concentration above the mixing layer: 1) the carry-over from previous days with the formation of residual layers, 2) physical and chemical processes involving particle growth, coalescing and settling, 3) transport events (Ferrero et al., 2007; McKendry et al, 2004, Maletto et al., 2003; Stratmann et al., 2003; McKendry and Lundgren, 2000). Factors 2 and 3 also affect particle size distribution. In this work the presence of the ML is found to be of crucial importance in influencing aerosol size, and the data in Table 1 show a non-homogeneous vertical dispersion of different broad size-classes. Figure 6 shows, as a function of particle diameter, the ratios of the number-concentration measured above the ML, to those measured at ground-level. Particles in the coarse fraction are less concentrated along height, and the largest ones reached the lowest values (less than $10 \%$ in winter). On the other hand, the percentage of fine particles reached a maximum value in the size range 0.5$0.65 \mu \mathrm{m}$ in the winter, and in the size range $1.0-1.6 \mu \mathrm{m}$ in the
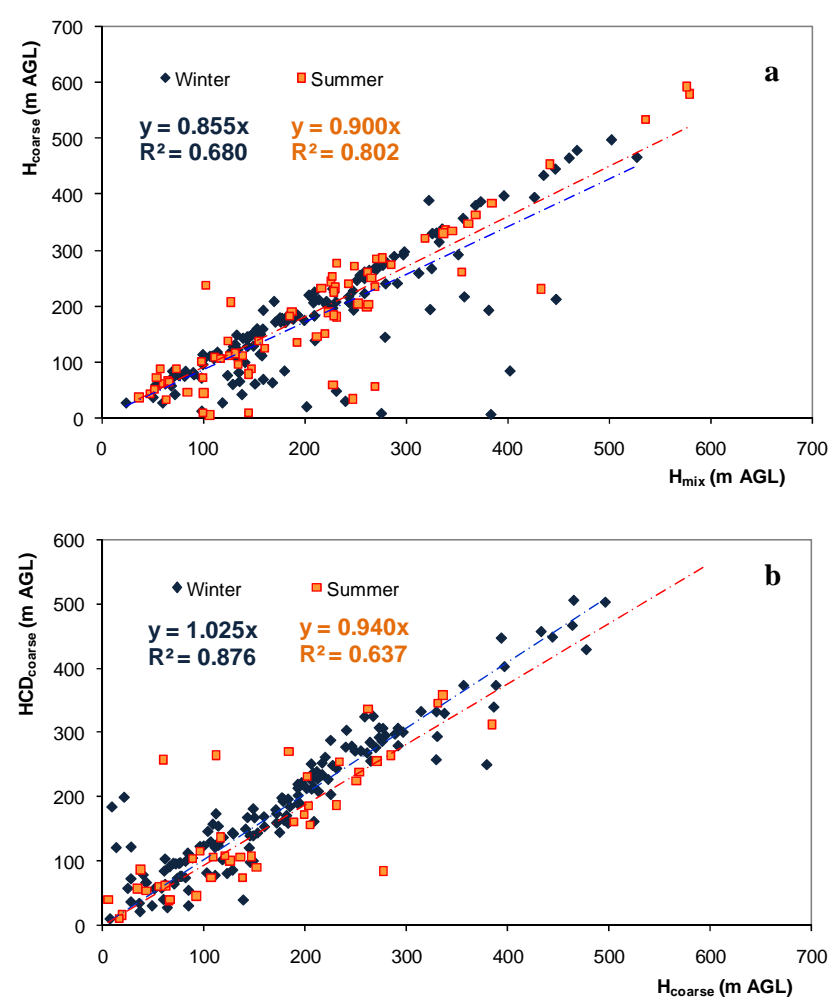

Fig. 7. The linear correlation between $H_{\text {mix }}$ and $H_{\text {coarse }}$ (a), and between $H_{\text {coarse }}$ and $\mathrm{HCD}_{\text {coarse }}(\mathbf{b})$ in the winter (DJF months; $\mathrm{N}$ profiles $=142$ ) and summer (JJA months; $\mathrm{N}$ profiles $=72$ ).

summer. The size-distribution changes along height, for both the fine and coarse fractions, are thus described by the mean particle diameter (MPD) calculated as follows:

$\mathrm{MPD}=\frac{\sum_{i} N_{i} D_{i}}{\sum_{i} N_{i}}$

where $N_{i}$ is the number concentration of particles within each size class, and $D_{i}$ its mean diameter.

Figure 2a-d shows typical examples of vertical profiles of fine and coarse particles and their MPD along height; MPDs of fine and coarse fractions display opposing forms of behaviour. The two types of behaviour will be discussed separately in the following sections.

\subsubsection{Coarse fraction behaviour}

Coarse particles are primarily emitted into the atmosphere by different sources (natural and anthropogenic, mainly resuspension); they undergo dry deposition by gravitational settling (Raes et al. 2000). This basic phenomenon influenced the balance between upward and downward mixing, making coarse particles unevenly distributed within the ML.

Coarse particle profiles were investigated by means of a gradient method; a mixing state for the coarse particles was 
Table 2. Statistics for MPD changes measured during winter (DJF months; N profiles $=142$ ) and summer (JJA months; $N$ profiles $=72$ ). MPD changes are obtained comparing data above the mixing height with ground-level data. FF=Fine Fraction, $\mathrm{CF}=$ Coarse Fraction. $\sigma=$ standard deviation, $\sigma_{m}=$ mean standard deviation.

\begin{tabular}{lllll}
\hline MPD relative changes & \multicolumn{2}{c}{ Winter } & \multicolumn{2}{c}{ Summer } \\
\hline & FF $\%$ & CF $\%$ & FF $\%$ & CF \% \\
mean & +2.1 & -14.9 & +3.9 & -10.7 \\
$\sigma_{m}$ & 0.1 & 0.6 & 0.3 & 1.0 \\
$\sigma$ & 1.3 & 6.1 & 1.7 & 7.5 \\
$\min$ & +0.3 & -1.8 & +0.3 & -1.4 \\
$25^{\circ}$ perc & +1.0 & -11.0 & +2.8 & -4.5 \\
$50^{\circ}$ perc & +1.8 & -14.3 & +3.3 & -9.1 \\
$75^{\circ}$ perc & +2.9 & -19.6 & +5.2 & -15.3 \\
$\max$ & +6.1 & -27.4 & +8.5 & -31.6 \\
\hline
\end{tabular}

defined ( $H_{\text {coarse }}$, Fig. $\left.2 \mathrm{c}\right)$. $H_{\text {coarse }}$ was found to be different from $H_{\text {mix }}$ in several profiles. Figure 7a compares $H_{\text {mix }}$ and $H_{\text {coarse }}$ for each profile in winter and summer. In summer, vertical distribution was rather uniform $\left(R^{2}=0.802\right.$, slope $=0.900)$; however, the winter revealed a lower $R^{2}$ $(0.680)$ and a higher discrepancy of the slope $(0.855)$ from the unit value. Weak boundary layer turbulence and low wind speed were the causes of this phenomenon, allowing the settling process to influence coarse profiles. Similar results were achieved by Maletto et al. (2003).

Under these conditions (lower values of $H_{\text {coarse }}$ compared to $\left.H_{\text {mix }}\right) H_{\text {mix }}$ is unsuitable as a proxy of $H_{\text {eff }}$ in PM estimation from satellites.

At the same time, it was found that the MPD of coarse mode decreased with height; from the ground, MPD remained rather constant along height (Fig. 2d), but, at $H_{\text {coarse }}$ MPD decreased as a result of sedimentation of the larger particles. We investigated the MPD profiles using a gradient method, and we defined $\mathrm{HCD}_{\text {coarse }}$ (height of changing diameter for coarse particles). A strong linear relationship with $H_{\text {coarse }}$ was found (Fig. 7b), especially in winter $\left(R^{2}=0.876\right.$, slope $\left.=1.025\right)$. In summer this relationship was weaker $\left(R^{2}=0.637\right.$, slope $\left.=0.940\right)$. On average, the sedimentation process was observed in $94 \%$ of cases in winter and in only $49 \%$ of cases in summer. In the other cases, no clear evidence of any reduction in MPD was found. Low windy conditions and higher stability in the winter favoured particle sedimentation, whereas higher atmospheric instability weakened particle sedimentation in the summer.

Comparing MPD data collected above the ML, with those data collected near ground-level, the mean change in MPD was $-14.9 \pm 0.6 \%$ in winter and $-10.7 \pm 1.0 \%$ in summer; maximum reductions were, respectively, $-27.4 \%$ and $-31.6 \%$ (Table 2).

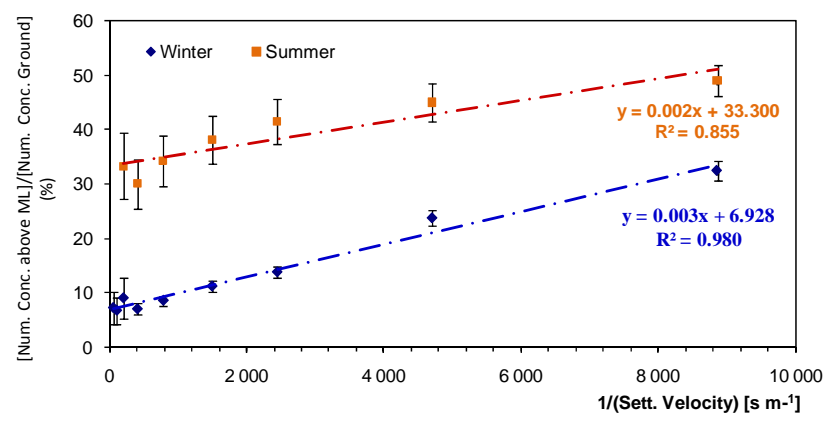

Fig. 8. Linear correlation between the percentage of each coarse size-class found above the ML, and the inverse of settling velocity in winter (a) (DJF months; N profiles $=142)$ and summer (b) (JJA months; $\mathrm{N}$ profiles $=72$ ).

As a result, retrieving inversion algorithms have to account for this first vertical dishomogeneity of aerosol size along height. Different coarse size classes, characterized by different scattering and absorption efficiencies, are not vertically distributed in an identical manner within and above the mixing layer.

This could be easily taken into account by simulating the sedimentation of coarse particles in stable conditions: the percentages of particle number concentration found above the ML (Fig. 6), for coarse size-classes only, can easily be correlated with the inverse of settling speed calculated for the same sizes $\left(R^{2}=0.980\right.$ in winter and $R^{2}=0.855$ in summer; Fig. 8).

\subsubsection{Fine fraction behaviour}

Unlike coarse particles, fine particles displayed an increase in MPD at the mixing height under stable conditions (Fig. 2b). We investigated the fine MPD profiles using a gradient method, and we defined the $\mathrm{HCD}_{\text {fine }}$ (height of changing diameter for fine particles). $H_{\text {mix }}$ and $\mathrm{HCD}_{\text {fine }}$ were directly compared to each other (Fig. 9) and were found almost always to coincide; they showed a high degree of correlation both in winter $\left(R^{2}=0.913\right.$, slope $\left.=1.052\right)$ and summer $\left(R^{2}=0.972\right.$, slope $\left.=1.048\right)$, with slopes close to one. Table 2 summarizes the average MPD increase, obtained by comparing data collected above the ML with data collected at ground level. An average increase in MPD of $+2.1 \pm 0.1 \%$ in winter and of $+3.9 \pm 0.3 \%$ in summer was discovered; maximum values were $+6.1 \%$ and $+8.5 \%$ respectively. This size change was repetitive and occurred in $82 \%$ of cases in the winter and in only $51 \%$ of cases in the summer.

At the same time as aerosol sizing was being performed, massive PM samples were collected at ground level, within the $\mathrm{ML}$, and above the ML. $\mathrm{NO}_{3}^{-}, \mathrm{SO}_{4}^{2-}$ and $\mathrm{NH}_{4}^{+}$were jointly analysed as reported in Sect. 2.1. Their average atmospheric concentrations are summarized in Table 3. $\mathrm{NO}_{3}^{-}$, $\mathrm{SO}_{4}^{2-}$ and $\mathrm{NH}_{4}^{+}$content in aerosol volume was found on 
Table 3. Mean atmospheric concentrations for $\mathrm{NO}_{3}^{-}, \mathrm{SO}_{4}^{2-}$ and $\mathrm{NH}_{4}^{+}$measured along vertical profiles. Concentrations measured above the mixing layer are normalized to ground pressure and temperature; $\sigma_{m}=$ mean standard deviation.

\begin{tabular}{lllllllll}
\hline Atmospheric concentrations $\left(\mu \mathrm{g} / \mathrm{m}^{3}\right)$ & \multicolumn{2}{c}{$\mathrm{NO}_{3}^{-}$} & \multicolumn{3}{c}{$\mathrm{SO}_{4}^{2-}$} & \multicolumn{2}{c}{$\mathrm{NH}_{4}^{+}$} \\
\hline & mean & $\sigma \mathrm{m}$ & mean & $\sigma \mathrm{m}$ & mean & $\sigma \mathrm{m}$ \\
Ground-level & 22.3 & 2.9 & 6.8 & 1.7 & 7.0 & 0.5 \\
Within the ML & 23.8 & 5.2 & 7.0 & 1.7 & 6.1 & 0.6 \\
Above the ML & 9.2 & 3.1 & 3.1 & 1.1 & 3.1 & 0.8 \\
\hline
\end{tabular}

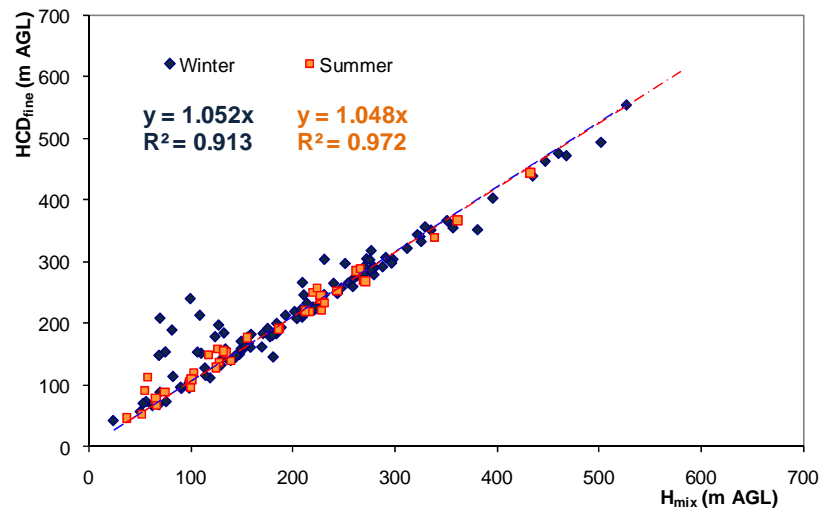

Fig. 9. Linear correlation between $H_{\text {mix }}$ and $\mathrm{HCD}_{\text {fine }}$ in the winter (DJF months; N profiles $=142$ ) and summer (JJA months; N profiles $=72$ ).

average to be $20 \%$ lower above the ML than at ground-level. Morgan et al. (2009) and Schenider at al. (2006) found a similar vertical gradient of inorganic ions along height, especially under stagnant conditions.

However, the respective contributions of $\mathrm{NO}_{3}^{-}, \mathrm{SO}_{4}^{2-}$ and $\mathrm{NH}_{4}^{+}$to their total was found to be fairly constant along the entire profile (from ground level to above the ML; Fig. 10ac) every time there was evidence of an increase in MPD.

During transport events, different MDP behaviour was discovered, associated with a sharp change in chemical composition above the ML. Figure 10d-f shows the advection of air masses over the ML from the Mediterranean Sea on 23 February 2007: these air masses were rich in sulphates (Fig. 10d), usually associated with fine particles, thus causing a sharp decrease in MDP above the ML (Fig. 10f). The mean change in MPD obtained by comparing data collected above the ML with ground-level data during transport events, was $-1.3 \pm 0.1 \%$.

$H_{\text {mix }}$ thus appeared to be a critical parameter with which to describe MPD changes in the lower troposphere both under stagnant conditions and during long-range transport events.

For this reason, optical retrieving inversion algorithms also have to account for this second vertical dishomogeneity, namely: aerosol size changes in the fine fraction. As confirmed by Wiegner et al. (2006), the extinction coefficient (which is a function of particle size and composition) is height-dependent. Thus in these cases, estimates of aerosol extinction at ground-level obtained by dividing the AOD by the $H_{\text {mix }}$ can fail.

Previous findings pointed to the need for a correct simulation of fine MPD changes along vertical profiles. In order to perform such a simulation, a complete size distribution, together with information about nucleation, coagulation, condensation and evaporation processes, is required (Laakso et al., 2007; Kulmala et al., 2004; Stratmann et al., 2003). Balloon launches, as a result of their discontinuous nature and payload limitations, cannot provide the continuous, comprehensive information required.

For this reason, we adopted a statistical approach in order to predict fine particle size distribution changes along height. A statistical approach has the advantage of not requiring physicochemical information, and also of taking account of transport events. A statistical approach to fine MPD changes is illustrated in the following section.

\subsection{Statistical modelling of fine fraction behaviour}

In the previous sections, we mentioned that particle size distribution varies according to height.

Since coarse particle $\left(d_{p}>1.6 \mu \mathrm{m}\right)$ behaviour is governed by the well-known sedimentation process, statistical modelling has been based on fine particle behaviour only.

The statistical model proposed in this section establishes a basis for assessing the size distribution changes for the fine fraction using a general law; this can be done parametrizing meteorological conditions so as to distinguish periods of highly stable conditions from other periods. Size distribution along the whole profile can be predicted starting simply from ground measurements (aerosol and meteorological) and from an estimation of $H_{\text {mix }}$.

We consider the relative contribution of a specific OPC size class in the fine fraction (FF) size range (six size classes are involved: $0.3-0.4 \mu \mathrm{m}, 0.4-0.5 \mu \mathrm{m}, 0.5-0.65 \mu \mathrm{m}, 0.65-$ $0.8 \mu \mathrm{m}, 0.8-1.0 \mu \mathrm{m}$ and $1.0-1.6 \mu \mathrm{m})$ to total particle concentration, i.e. to the sum of the number concentrations of the six size categories mentioned. The statistical model analyses the proportions of PM classified according to particle size on 
Relative contribution of $\mathrm{NO}_{3}{ }^{-}, \mathrm{SO}_{4}{ }^{2-}, \mathrm{NH}_{4}{ }^{+}$to the secondary inorganic ions - Milan - Ground

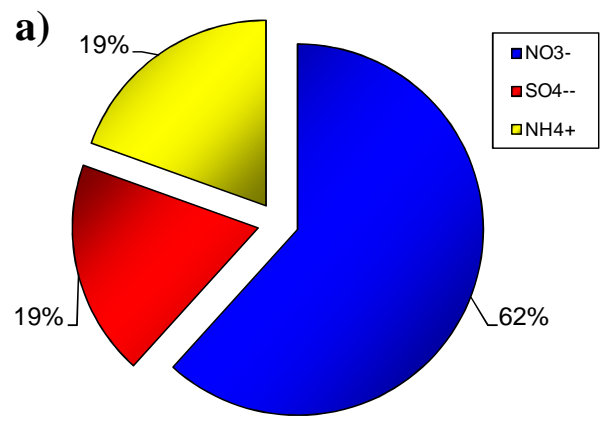

Relative contribution of $\mathrm{NO}_{3}{ }^{-}, \mathrm{SO}_{4}{ }^{2-}, \mathrm{NH}_{4}{ }^{+}$to the secondary

c) inorganic ions - Milan - Over the Mixing Laver

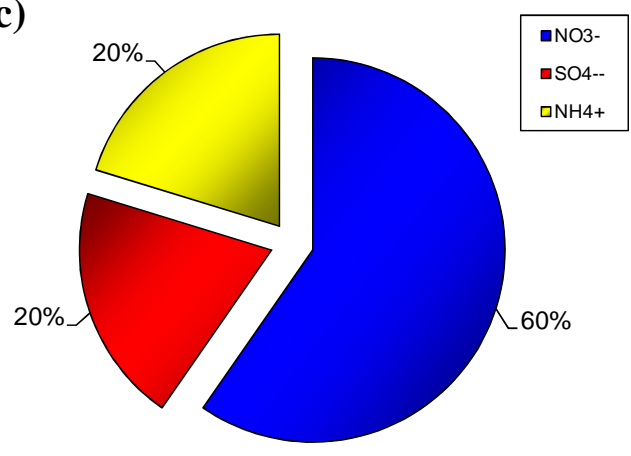

NOAA HYSPLIT MODEL

e) Backward trajectories ending at 09 UTC 23 Feb 07 e) GDAS Meteorological Data

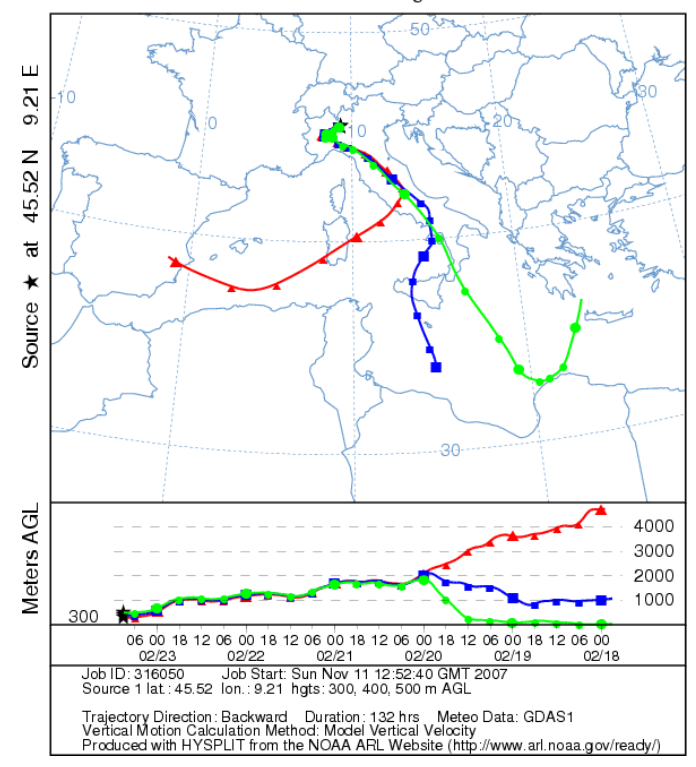

Relative contribution of $\mathrm{NO}_{3}{ }^{-}, \mathrm{SO}_{4}{ }^{2-}, \mathrm{NH}_{4}{ }^{+}$to the secondary inorganic ions - Milan - Within the Mixing Laver

b)

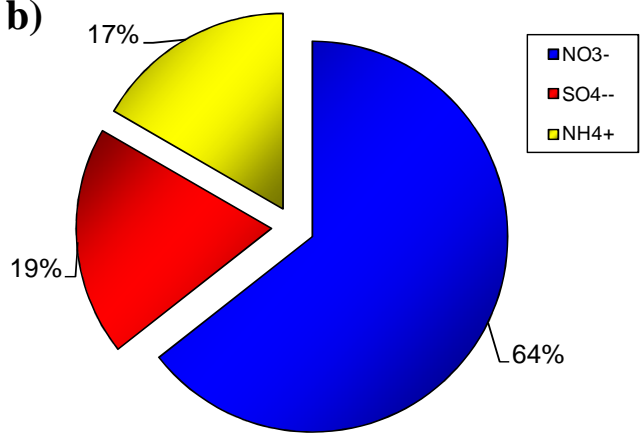

Relative contribution of $\mathrm{NO}_{3}{ }^{-}, \mathrm{SO}_{4}{ }^{2-}, \mathrm{NH}_{4}{ }^{+}$to the secondary

d) inorganic ions- Milan - Transport event over the ML
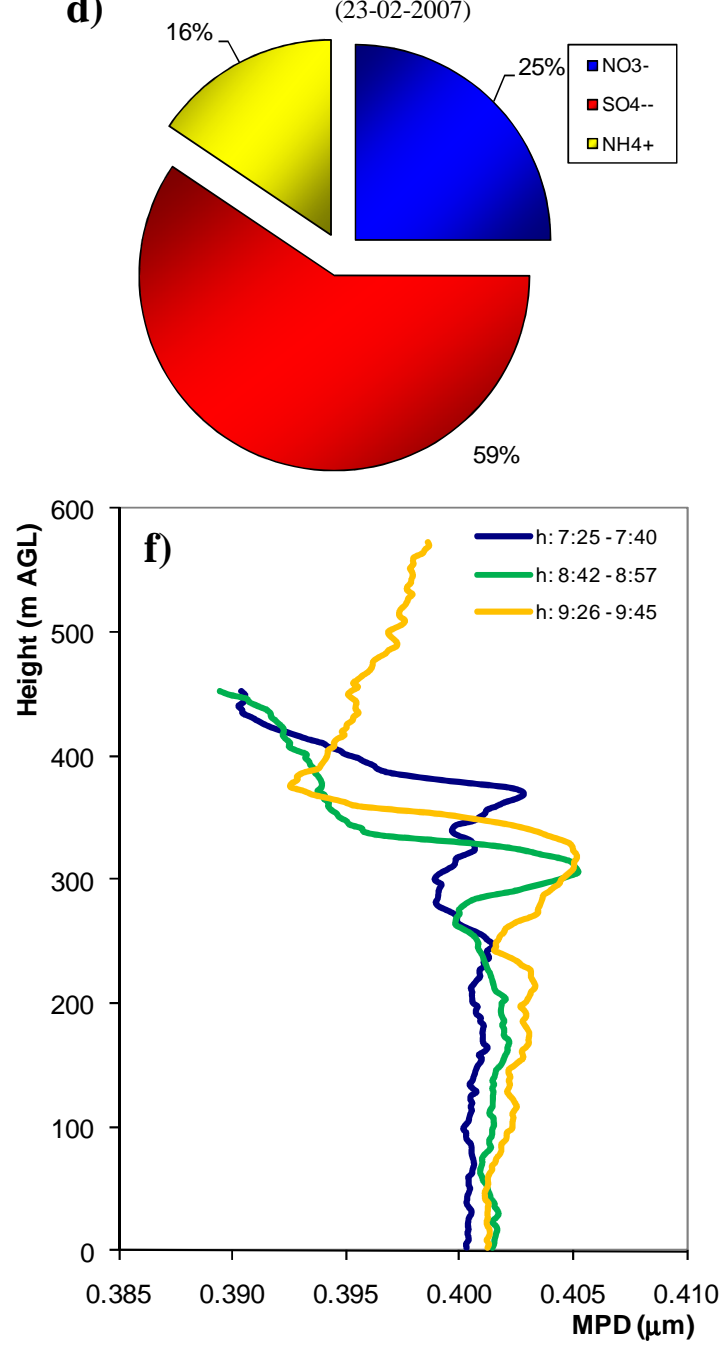

Fig. 10. Percentages of $\mathrm{NO}_{3}^{-}, \mathrm{SO}_{4}^{2-}$ and $\mathrm{NH}_{4}^{+}$compared to their total, measured in Milan at ground-level (a), within the ML (between ground and mixing height) (b) and above it (c) when an increase in MPD was observed in the fine fraction $\left(d_{p}<1.6 \mu \mathrm{m}\right)$. Panel (d) shows relative values of $\mathrm{NO}_{3}^{-}, \mathrm{SO}_{4}^{2-}$ and $\mathrm{NH}_{4}^{+}$during the transport event of $23^{r d}$ February 2007. Back trajectories and MPD during the transport event are shown in panels (e) and (f). 
the basis of the theory of compositional data. Compositional data consist of parts that sum up to unity (Aitchison, 1986; Billheimer et al., 2001). Meteorological conditions are crucial antecedents for any pollutant structure: different external conditions can be taken into account by building homogeneous groups using a clustering algorithm adapted to the treatment of compositional data (Bruno and Greco, 2008). Separate models for each group are estimated in order to study the evolution of particle size distribution along the vertical profiles.

We considered 139 launches chosen from the entire dataset: a launch was selected if its profile above the ML height could be traced. The selected launches have been clustered into 4 different typologies. Each group is characterized by very different specific external conditions, which are summarized in Table 4. This table shows the mean value per group of a series of variables (aerosol and meteorological).

Groups A and B mainly contain winter launches, whereas groups $\mathrm{C}$ and $\mathrm{D}$ mainly contain launches measured on summer days. The differences between summer and winter groups are evident; the mean number concentration of particles is noticeably higher in the winter groups (A-B), as is the ground-level pollution summarised by $\mathrm{PM}_{1}$ and $\mathrm{PM}_{2.5} \mathrm{lev}$ els. Since groups are made up of a large number of launches characterized by a large number of observations, the estimation of models based on this amount of data can be very timeconsuming. If homogeneity within a group is high, limiting the number of launches on which to estimate the model involves a tolerable loss of information, and we benefit from savings in computational costs. For these reasons, the prototype model for each sub-group is estimated on data obtained from 8 launches. The eight launches selected within each group are summarised in Table 5. This table enables us to check that the external conditions of the selected launches are similar to those of the parent groups shown in Table 4 .

Tables 6 and 7 show the average relative size distribution within each group. The first size class constitutes more than $70 \%$ of the total counts in all groups, whereas the last three size classes account for less than 5\% of the total. Groups $\mathrm{A}-\mathrm{B}$ and $\mathrm{C}-\mathrm{D}$ differ in behaviour with respect to the second size-class $(0.4-0.5 \mu \mathrm{m})$ whose contribution is greater in winter groups (about 20\%) than in summer groups (about $15 \%)$. However, the most interesting feature of the table is the predominance of the finest particles in group $\mathrm{C}$. This is attributable to transport situations, and thus group $\mathrm{C}$ represents a cluster of vertical profiles affected by transport event, and characterized by the lowest mean sea level pressure among the various groups (Tables 4 and 5), a condition that favours the intrusion of diverse air masses. These considerations apply both to the full-size groups (Table 6) and to the subsets (Table 7) selected for subsequent analysis.

For each launch, the ML height, the maximum height reached by the balloon, and the number of collected measurements, differ. In order to overcome this heterogeneity, each measurement was considered in relation to its distance from the specific ML height for a generic launch $k\left(H_{\operatorname{mix}(k)}\right)$. Therefore, each height value has been transformed into a standardised value $\left(X_{k h}\right)$ according to

$X_{k h}=\frac{\operatorname{Height}_{k h}-H_{\operatorname{mix}(k)}}{H_{\operatorname{mix}(k)}}$

where Height ${ }_{k h}$ is the height of the $h$-th measurement for launch $k$.

The behaviour of the observed vertical profiles in relation to standardised height rather than absolute height, tends to be more homogeneous. This strengthens the conjecture that $H_{\text {mix }}$ is the crucial quantity in describing vertical profiles. In the following subsection, we construct a statistical model for the behaviour of all size classes along height. The proposed model is capable of estimating the characteristic vertical profile generating each launch within a group. Since data are compositional, the model has to take the sum-to-one constraint into account.

The merit of proposing a statistical approach for modelling vertical profiles consists in estimating parameters with a degree of credibility which is managed by probability. The uncertainty of results can therefore be assessed, and the statistical model can be used with caution, as a general paradigm.

\subsubsection{A hierarchical model for homogeneous groups}

A hierarchical model is constructed separately for each homogeneous group described in Table 7 (group-specific model). Hierarchical models are an effective tool for building complex models from relatively simple sub-models, each of which is interpreted as a level of the resulting hierarchy. The Bayesian framework is highly suited to this kind of model (Wikle et al., 1998). For each group-specific hierarchical model, the variable modelled is $y_{k h r}$, i.e. the particle number concentration per vertical profile $k$, height $h$ and size class $r$, $(r=1, \ldots, 6)$.

The first level of the model is:

$\boldsymbol{y}_{k h} \mid \boldsymbol{p}_{k h}, n_{k h} \sim \operatorname{Multinomial}\left(\boldsymbol{p}_{k h, n_{k h}}\right)$

$k=1, \ldots, 8 ; h=1, \ldots, H_{k}$

where $\boldsymbol{y}_{k h}$ and $n_{k h}=\sum_{r=1}^{6} y_{k h r}$ are respectively a 6dimensional vector containing the particle number concentrations and the total particle number concentrations at height $h$ for launch $k$. The maximum height observed for each launch is denoted by $H_{k}$. The multinomial distribution is appropriate in this case since it permits us to model concentration data with a sum constraint (the number concentration of particles at height $h$ for vertical profile $k$, denoted as $n_{k h}$ ).

The multinomial distribution is parameterised by $\boldsymbol{p}_{k h}=\left(p_{k h 1}, p_{k h 2}, \ldots, p_{k h 6}\right)$, the model parameters representing the relative contribution of each OPC size class to the whole FF number concentration $\left(\boldsymbol{p}_{k h}=\boldsymbol{y}_{k h} / n_{k h}\right)$. The sum to unit constraint $\left[\sum_{r=1}^{6} p_{k h r}=1\right.$ in (3)] suggests the use of an additive log-ratio (alr) transformation (Aitchison, 
Table 4. Descriptive statistics for each homogeneous group.

\begin{tabular}{lllllllll}
\hline & Nr. of Launches & $\begin{array}{l}\text { Mean part. conc. } \\
\left(\mathrm{cm}^{-3}\right)\end{array}$ & $\begin{array}{l}\text { MLH } \\
(\mathrm{m})\end{array}$ & $\begin{array}{l}\text { Temp. } \\
\left({ }^{\circ} \mathrm{C}\right)\end{array}$ & $\begin{array}{l}\text { Humid. } \\
(\%)\end{array}$ & $\begin{array}{l}\text { Pressure } \\
(\mathrm{hPa})\end{array}$ & $\begin{array}{l}\mathrm{PM}_{1} \\
\left(\mu \mathrm{g} / \mathrm{m}^{3}\right)\end{array}$ & $\begin{array}{l}\mathrm{PM}_{2.5} \\
\left(\mu \mathrm{g} / \mathrm{m}^{3}\right)\end{array}$ \\
\hline Group A & 39 & 425.7 & 144.62 & 4.79 & 63.78 & 1006.27 & 38.78 & 104.41 \\
Group B & 56 & 428.5 & 240.75 & 7.99 & 56.09 & 972.31 & 28.79 & 80.66 \\
Group C & 24 & 81.84 & 279.92 & 19.00 & 51.57 & 940.21 & 20.55 & 38.39 \\
Group D & 20 & 58.31 & 203.80 & 23.07 & 44.73 & 977.51 & 14.89 & 28.59 \\
\hline
\end{tabular}

Table 5. Descriptive statistics for homogeneous sub-groups entering in model estimation.

\begin{tabular}{lllllllll}
\hline & Nr. of Launches & $\begin{array}{l}\text { Mean part. conc. } \\
\left(\mathrm{cm}^{-3}\right)\end{array}$ & $\begin{array}{l}\text { MLH } \\
(\mathrm{m})\end{array}$ & $\begin{array}{l}\text { Temp. } \\
\left({ }^{\circ} \mathrm{C}\right)\end{array}$ & $\begin{array}{l}\text { Humid. } \\
(\%)\end{array}$ & $\begin{array}{l}\text { Pressure } \\
(\mathrm{hPa})\end{array}$ & $\begin{array}{l}\mathrm{PM}_{1} \\
\left(\mu \mathrm{g} / \mathrm{m}^{3}\right)\end{array}$ & $\begin{array}{l}\mathrm{PM}_{2.5} \\
\left(\mu \mathrm{g} / \mathrm{m}^{3}\right)\end{array}$ \\
\hline Group A & 8 & 393.6 & 132.13 & 5.37 & 62.59 & 1001.59 & 34.67 & 105.13 \\
Group B & 8 & 445.5 & 261.75 & 3.24 & 56.90 & 974.51 & 39.00 & 78.88 \\
Group C & 8 & 46.04 & 281.25 & 10.95 & 51.52 & 982.80 & 18.40 & 29.82 \\
Group D & 8 & 64.45 & 243.25 & 23.30 & 42.17 & 974.24 & 14.29 & 26.81 \\
\hline
\end{tabular}

1986) in order to transform parameters $\boldsymbol{p}_{k h}$ (defined in the 6-dimensional simplex space $\nabla^{6}$ ) to the unconstrained Euclidean space $\mathfrak{R}^{5}$. We denote the transformed vector using the alr function as the 5-dimensional vector $\boldsymbol{z}_{k h}=\operatorname{alr}\left(\boldsymbol{p}_{k h}\right)$, where:

$z_{k h r}=\ln \left(\frac{p_{k h r}}{p_{k h 6}}\right) \quad r=1, \ldots, 5$

In general, given an alr-transformed vector, back transformation from $\mathfrak{R}^{5}$ to $\nabla^{6}$ is achieved via the $\quad a l r^{-1}$ function: $\quad a l r^{-1}\left(z_{k h}\right)=\boldsymbol{p}_{k h} \quad$ where $p_{k h r}=\exp \left(z_{k h r}\right) /\left(1+\sum_{r=1}^{5} \exp \left(z_{k h r}\right)\right) \quad$ and $p_{k h 6}=1 /\left(1+\sum_{r=1}^{5} \exp \left(z_{k h r}\right)\right)$.

Further modelling regards the $z_{k h r}$ variables. Each $z_{k h r}$ is seen as a central value plus a Gaussian error with a 0 mean and variance which is specific to vertical profile and size class:

$z_{k h r}=\mu_{k h r}+\varepsilon_{k h r}$ where $\varepsilon_{k h r} \sim N\left(0, \sigma_{k r}^{2}\right)$

The mean value $\mu_{k h r}$ represents the parameter in question, which depicts the theoretical behaviour of each size class $r$ along height. It is modelled as a function of the new standardised height $X_{k h}$ (Eq. 2). This function consists of the sum of two fundamental terms: a constant profile-size class parameter $\gamma_{k r}$, and a weighted sum of powers of the standardised height used to describe the non-linear relationship linking $X_{k h}$ and size-classes:

$\mu_{k h r}=\gamma_{k r}+\sum_{j=1}^{J} \beta_{j k r} X_{k h}^{j} \quad j=1, \ldots, J$ where $\gamma_{k r}$ and $\left\{\beta_{j k r}, j=1, \ldots, J\right\}$ are launch-specific parameters that capture the mean and shape of the $r$-th size class of the $k$-th vertical profile (with respect to the reference sizeclass). The four group-specific hierarchical models differ only in the definition of the functional relationship between vertical profile and standardised height. The degree of the polynomial is denoted by $J$ and is set at either 3 or 4 for each group-specific model.

This equation describes the behaviour of the relative contribution of the original OPC FF size-classes along the standardized height. It could be used to predict size distribution along the entire profile, starting from the knowledge of ground truths (aerosol and meteorological) and from ML height. However, at the first level of hierarchy, the $y_{k h r}$ model is launch-specific dependent (a function of $\gamma_{k r}$ and $\beta$ jkr which are launch-k dependent). The second and third levels of the hierarchy are constructed in order to find a general model for each group .The profile-size class parameters $\left(\gamma_{k r}\right.$ and $\left.\beta_{j k r}\right)$ characterize the second level of the hierarchical model. Second-level parameters are still modelled as the sum of a central value and a normal zero-mean error:

$\beta_{j k r}=\beta_{j r}+\delta_{\beta_{j k r}}$ where $\delta_{\beta_{j k r}} \sim N\left(0, \sigma_{\beta_{j r}}^{2}\right) j=1, \ldots, J$

$\gamma_{k r}=\gamma_{r}+\delta_{\gamma_{k r}}$ where $\delta_{\gamma_{k r}} \sim N\left(0, \sigma_{\gamma_{r}}^{2}\right)$

In other words, every $k$-th launch-specific parameter of (6) $\left(\gamma_{k r}\right.$ and $\left.\left\{\beta_{j k r}, j=1, \ldots, J\right\}\right)$ is conceived as the sum of a common group parameter $\left(\gamma_{r}\right.$ and $\left.\left\{\beta_{j r}, j=1, \ldots, J\right\}\right)$ plus a random error that represents the deviation from a groupspecific central value. 
Table 6. Average size distribution in the homogeneous groups.

\begin{tabular}{llllllll}
\hline & Nr. of Launches & $0.3-0.4 \mu \mathrm{m}$ & $0.4-0.5 \mu \mathrm{m}$ & $0.5-0.65 \mu \mathrm{m}$ & $0.65-0.8 \mu \mathrm{m}$ & $0.8-1 \mu \mathrm{m}$ & $1-1.6 \mu \mathrm{m}$ \\
\hline Group A & 39 & 0.7340 & 0.2101 & 0.0443 & 0.0075 & 0.0031 & 0.0010 \\
Group B & 56 & 0.7158 & 0.2201 & 0.0503 & 0.0087 & 0.0038 & 0.0012 \\
Group C & 24 & 0.7822 & 0.1507 & 0.0381 & 0.0131 & 0.0106 & 0.0053 \\
Group D & 20 & 0.7336 & 0.1569 & 0.0576 & 0.0234 & 0.0195 & 0.0090 \\
\hline
\end{tabular}

Table 7. Average size distribution in homogeneous sub-groups included in model estimation.

\begin{tabular}{llllllll}
\hline & Nr. of Launches & $0.3-0.4 \mu \mathrm{m}$ & $0.4-0.5 \mu \mathrm{m}$ & $0.5-0.65 \mu \mathrm{m}$ & $0.65-0.8 \mu \mathrm{m}$ & $0.8-1 \mu \mathrm{m}$ & $1-1.6 \mu \mathrm{m}$ \\
\hline Group A & 8 & 0.7139 & 0.2285 & 0.0470 & 0.0069 & 0.0028 & 0.0009 \\
Group B & 8 & 0.7259 & 0.2152 & 0.0458 & 0.0081 & 0.0037 & 0.0013 \\
Group C & 8 & 0.8029 & 0.1384 & 0.0346 & 0.0117 & 0.0084 & 0.0040 \\
Group D & 8 & 0.7357 & 0.1573 & 0.0559 & 0.0227 & 0.0194 & 0.0089 \\
\hline
\end{tabular}

At the third level of hierarchy, each group is characterised by the group hyperparameters $\boldsymbol{\gamma}$ and $\boldsymbol{\beta}_{j}$

$\boldsymbol{\beta}_{j} \mid \boldsymbol{\Sigma}_{\beta_{j}} \sim \operatorname{MVN}\left(\mathbf{0}, \boldsymbol{\Sigma}_{\beta_{j}}\right) \quad \boldsymbol{\beta}_{j}: 5$-dimensional vector

$\boldsymbol{\gamma} \mid \boldsymbol{\Sigma}_{\gamma} \sim \operatorname{MVN}\left(\mathbf{0}, \boldsymbol{\Sigma}_{\gamma}\right) \quad \boldsymbol{\gamma}: 5$-dimensional vector

These group-specific parameters are the main focus of inference, because they describe the typical behaviour characterising each group. Model hierarchy is completed by specifying Inverse Wishart distributions $I W(\boldsymbol{I}, 5)$ for the covariance matrices in Eqs. (9) and (10) and Inverse Gamma distributions $I G(.001,1000)$ for the variance parameters in Eqs. (5), (7) and (8), i.e. equivalent to non-informative priors.

Model complexity is such that analytical estimation is not feasible. Model estimation is conducted by simulation via the MCMC algorithms implemented in OpenBugs Software. Solutions are accepted after having checked convergence using standard techniques. Inference is based on 10000 postconvergence samples, after 30000 burn-in iterations. The degree of the polynomial in (6) has been selected using the Deviance Information Criterion (DIC) (Spiegelhalter et al., 2002); a third grade polynomial has been chosen for groups A, B and C, while a fourth grade polynomial has been chosen for group D. In particular, transformed values $a l r^{-1}(\boldsymbol{\gamma})$ vectors are the model counterpart of the average relative contribution of each size-class in homogeneous sub-groups in model estimation reported in Table 7, and their estimation is summarized in Table 8, which also reports $95 \%$ credibility intervals. Such intervals contain the empirical average relative size-distribution characterising both the full-size groups (Table 6) and the subsets selected for model estimation (Table 7). This shows how statistical modelling enables us to compute uncertainty measures of estimated values that give results that are more thorough than mere descriptive syntheses of data. The outputs of the hierarchical statistical model include the estimated MPD values corresponding to the empirical values (Eq. 1). The MPD increase estimated using the model is $1.6 \pm 0.4 \%$ for group $\mathrm{A} ; 2.2 \pm 0.5 \%$ for group $\mathrm{B}$; $-2.0 \pm 0.5 \%$ for group $\mathrm{C}$ and $6.1 \pm 1.2 \%$ for group $\mathrm{D}$, in accordance with experimental evidence highlighted in the previous sections.

The 4 panels in Fig. 11 show the vertical profiles estimated using the model for each group. Profiles of relative size-distribution are represented as deviations from the estimated $\gamma$ values and centred in $1 / 6$, which is the centre of a 6-dimensional simplex. The figure describes the shape of the prototype vertical profile for each group. This figure reveals the different characteristic behaviour of groups A, B and D, compared to that of group C. Results for groups A, B and D represent three models of MPD increase along height. There is clearly a considerable decrease in the relative contribution of the finest particles (1st size-class) along height. On the contrary, group $\mathrm{C}$ is characterized by an increase in the first size-class above the ML.

However, the comparison between vertical profiles based on Fig. 11 does not take account of the uncertainty characterising the results.

Uncertainty assessment can be appreciated with the help of Fig. 12, which shows $80 \%$ credibility bands for each sizeclass in groups $\mathrm{A}$ (in red) and $\mathrm{C}$ (in blue). We can appreciate the results of model estimation by showing the nonoverlapping bands above the ML among A, B, D groups and the transport group $\mathrm{C}$. 
Table 8. Posterior credibility intervals of $\operatorname{alr}^{-1}(\gamma)$, i.e. the estimated average size distribution.

\begin{tabular}{|c|c|c|c|c|c|c|}
\hline & $0.3-0.4 \mu \mathrm{m}$ & $0.4-0.5 \mu \mathrm{m}$ & $0.5-0.65 \mu \mathrm{m}$ & $0.65-0.8 \mu \mathrm{m}$ & $0.8-1 \mu \mathrm{m}$ & $1-1.6 \mu \mathrm{m}$ \\
\hline Group A & $0.7151(0.6941,0.7669)$ & $0.2272(0.1682,0.2763)$ & $0.0466(0.0329,0.0597)$ & $0.0072(0.0054,0.0093)$ & $0.0028(0.0023,0.0034)$ & $0.0009(0.0008,0.001)$ \\
\hline Group B & $0.7214(0.6581,0.778)$ & $0.2171(0.1757,0.2867)$ & $0.0479(0.0351,0.0651)$ & $0.0078(0.006,0.0103)$ & $0.0031(0.0025,0.0038)$ & $0.0011(0.0009,0.0015)$ \\
\hline Group C & $0.7989(0.7616,0.8303)$ & $0.1401(0.1165,0.1768)$ & $0.0341(0.0279,0.0416)$ & $0.0109(0.0092,0.0129)$ & $0.0081(0.0069,0.0097)$ & $0.0037(0.0033,0.0042)$ \\
\hline Group D & $0.7336(0.6205,0.7976)$ & $0.1586(0.1005,0.2348)$ & $0.0517(0.0313,0.0827)$ & $0.0207(0.0127,0.0284)$ & $0.0181(0.0104,0.0201)$ & $0.0074(0.0061,0.0091)$ \\
\hline
\end{tabular}

Group A

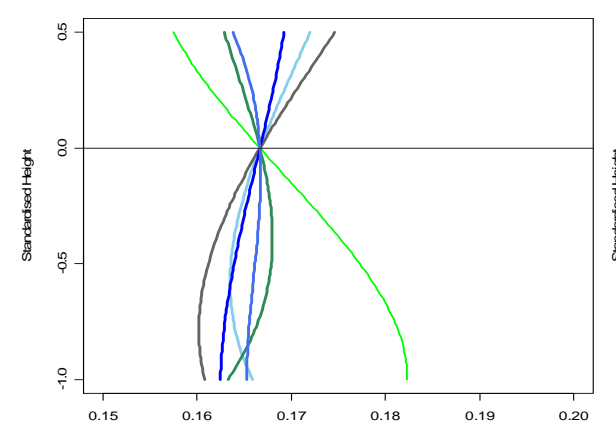

- 1st Class - 2nd Class - 3rd Class - 4th Class - 5th Class - 6th Class

\section{Group B}

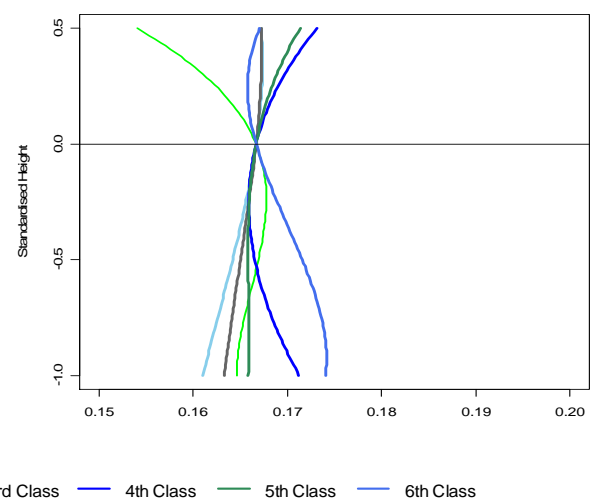

Group D

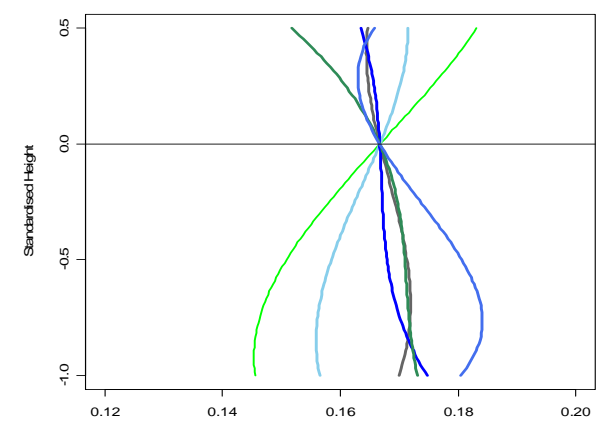

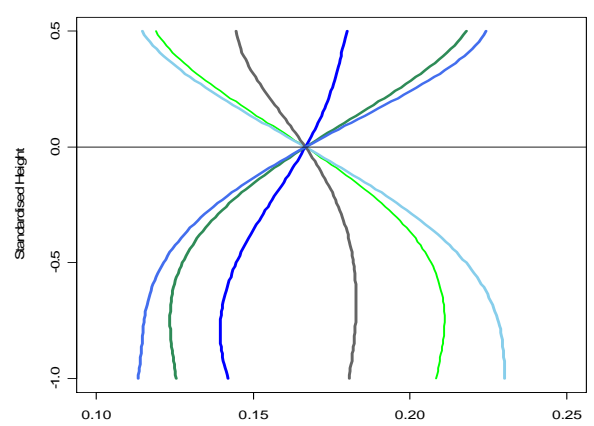

Fig. 11. Typical centred vertical profiles estimated using the statistical hierarchical model.

\section{Conclusions}

Vertical profiles of aerosol number size distribution and meteorological parameters were measured over Milan during field campaigns lasting a period of three years (2006-2008).

The main goal of the vertical profiles approach was to investigate the behaviour of aerosol along height and time. This approach offered information about atmospheric dispersal conditions and the evolution of mixing height together with aerosols' properties.

Mixing height was calculated from aerosol, potential temperature and relative humidity profiles showing a noticeable correlation between atmospheric particle dispersion and meteorological parameters; differences among different mixing height estimation techniques were lower than $40 \mathrm{~m}$. The mixing height evolution along daytime was characterized by low potential atmospheric dispersion in winter, when mixing height remained costrained into the first hundred of meters. The measured mixing height made it possible to account for the importance of meteorological effects related to atmospheric pollution in urban areas, using experimental data. During the winter in Milan, the mixing height does not reach any great altitude. $H_{\text {mix }}$ growth speed was also investigated, and a clear temporal development was calculated for winter and summer, reaching values of between $150-200 \mathrm{~m} / \mathrm{h}\left(95^{\circ}\right.$ percentile $=282 \mathrm{~m} / \mathrm{h})$ at noon in winter, to $300 \mathrm{~m} / \mathrm{h}\left(95^{\circ}\right.$ percentile $=338 \mathrm{~m} / \mathrm{h}$ ) in the early morning in summer. 
$1^{\text {st }}$ Class
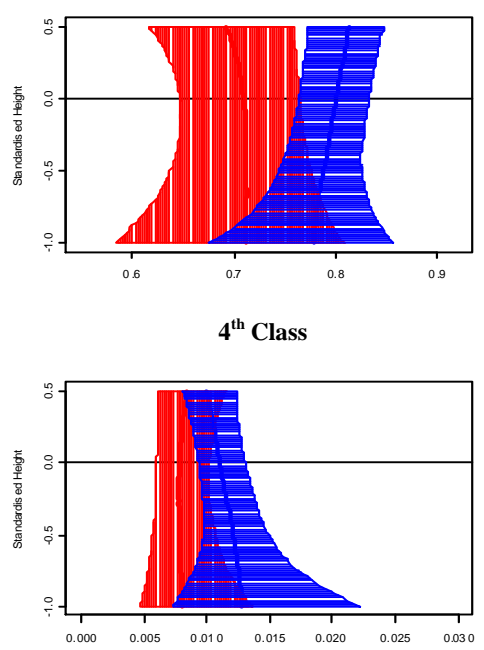

$2^{\text {nd }}$ Class
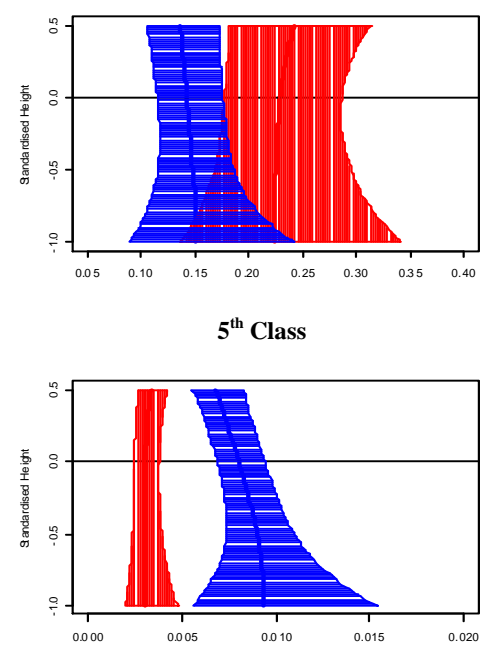

$3^{\text {rd }}$ Class
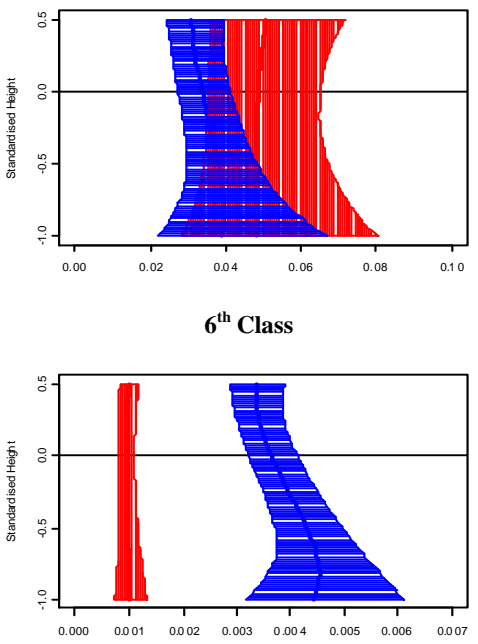

Fig. 12. $80 \%$ credibility bands for typical vertical profiles estimated for groups A (red) and C (blue).

Vertical profiles also enabled us to investigate aerosol number size distribution and chemical composition along height, which can be useful when trying to understand changes in particles' properties linked to their spatial and temporal evolution.

Aerosol profiles showed, firstly, the presence of a nonnegligible aerosol loading above the ML which reached $30 \pm 2 \%$ and $39 \pm 2 \%$ of aerosol volume $\mathrm{V}_{1}\left(d_{p}<1 \mu \mathrm{m}\right)$ on the ground in winter and summer; for the same seasons and with aerosol volume $\mathrm{V}_{10}\left(d_{p}<10 \mu \mathrm{m}\right)$, the percentages of aerosol loading above the mixing height were $20 \pm 1 \%$ and $37 \pm 3 \%$. These results point to the need to account for aerosol loading above the mixing height in satellite applications designed to estimate ground PM concentrations.

Aerosol profiles also evidenced non-homogeneous aerosol behaviour (size and composition) along height. Fine and coarse particle were distributed differently at different heights of the mixing layer. A settling process influenced the balance between the upward and downward mixing of coarse particles, shaping their vertical profiles; as a result, sedimentation caused a lower mixing-state of coarse particles compared to that of fine ones. There was also a decrease in the mean diameter of coarse particles along height $(-14.9 \pm 0.6 \%$ and $-10.7 \pm 1.0 \%$ in winter and summer). On the opposite hand, fine particles showed an increase in their mean diameter above the mixing height, under stable atmospheric conditions. The measured increase was on average $+2.1 \pm 0.1 \%$ and $+3.9 \pm 0.3 \%$ in winter and summer, respectively. Transport events caused a decrease in fine-fraction size associated with a sharp change in aerosol chemical composition.

These results show that the simple use of $H_{\text {mix }}$ in PM retrieval algorithms, as well as the assumptions of vertically homogeneous aerosol properties, can lead to errors in remote sensing applications. Different sized classes characterized by different scattering and absorption efficiencies, are not identically distributed vertically within and above the mixing layer. As a consequence, some from of parametrization is needed in order to account for size distribution changes along height.

This was easily achieved for coarse particles, by relating the percentages of particle number concentration found above the ML with the inverse of settling speed calculated for the same sizes $\left(R^{2}=0.980\right.$ in winter and and $R^{2}=0.855$ in summer).

For fine particles, however, we require knowledge of the complete size distribution, together with information about the nucleation, coagulation, condensation and evaporation processes. Hence, the typical particle size changes along height in the Po Valley's lower troposphere, for fine particles, was parametrized, by a statistical approach. This was achieved by developing a statistical model as a tool for handling similar data sets. All vertical profiles were together employed in a probabilistic model, after a clustering procedure and a process of standardisation in relation to the mixing height. The resulting model was able to predict particle properties along height starting from ground (aerosol and meteorological) parameters and $H_{\text {mix }}$ measurements. This was performed under different meteorological conditions.

It proved possible to compute the model counterpart for size distribution and MPD increase of the fine fraction. The chosen model estimated the following changes in the mean diameter of fine particles: $+1.6 \pm 0.4 \%$ for cluster $\mathrm{A}$ (winter); $+2.2 \pm 0.5 \%$ for cluster B (winter); $-2.0 \pm 0.5 \%$ for cluster C (transport events) and $+6.1 \pm 1.2 \%$ for cluster $\mathrm{D}$ (summer); these estimations reflect experimental results. 
The methodology we developed (both experimental and modelling approaches) produced a considerable amount of useful information based on low-cost, robust techniques.

This application clearly revealed that large data sets of vertical profiles can be used to support the development of new models, as well as to validate their outputs. These results derived from the collection of long-term data series, thus avoiding the common limit of direct sampling along vertical profiles, namely the temporal significance of such measurements and their interpretations.

Acknowledgements. This paper sets out certain results of the Italian QUITSAT project (Air Quality by Integrated measurements from Earth, Satellites and chemical-transport modelling; Italian Space Agency financed); the project's main goal was to estimate PM ground concentrations from satellite data pertaining to the Po Valley.

This study was partially funded by the AERA foundation, Fondazione Fratelli Confalonieri, the SITECOS (MIUR financed) project and the 2006 PRIN-MIUR grant (project no. 2006139812.003, sector: Economics and Statistics).

The research leading to this paper has also been partially funded by a 2008 grant (Project no. 2008CEFF37-001, sector:13: Economics and Statistics) for research of national interest by the Italian Ministry of the University and Scientific and Technological Research.

Edited by: W. Birmili

\section{References}

Aitchison, J.: The Statistical Analysis of Compositional Data, New York, USA, Chapman \& Hall, 416 pp., 1986.

Amiridis, V., Melas, D., Balis, D. S., Papayannis, A., Founda, D., Katragkou, E., Giannakaki, E., Mamouri, R. E., Gerasopoulos, E., and Zerefos, C.: Aerosol Lidar observations and model calculations of the Planetary Boundary Layer evolution over Greece, during the March 2006 Total Solar Eclipse, Atmos. Chem. Phys., 7, 6181-6189, 2007,

http://www.atmos-chem-phys.net/7/6181/2007/.

Angelini F., Barnaba F., Landi T.C., Caporaso L., and Gobbi G.P.: Study of atmospheric aerosols and mixing layer by lidar. Radiat. Prot. Dosim., 137, No 3-4, 275-279, 2009.

Baars H., Ansmann A., Engelmann R., and Althausen D.: Continuous monitoring of the boundary-layer top with lidar. Atmos. Chem. Phys., 8, 7281-7296, 2008, http://www.atmos-chem-phys.net/8/7281/2008/.

Billheimer, D., Guttorp, P., Fagan, W. (2001). Statistical Interpretation of Species Composition. J. Am. Stat. Assoc., 96, 1205-1214.

Bruno F. and Greco F.: Clustering compositional data trajectories, in: Proceedings of CODAWORK'08, edited by: Daunis-iEstadella, J. and Martín-Fernández, J. A.,The 3rd Compositional Data Analysis Workshop, 27-30 May, University of Girona, Girona (Spain), CD-ROM (ISBN: 978-84-8458-272-4), 11 pp., 2008.

Campanelli, M., Delle Monache, L., Malvestuto, V., and Olivieri, B.: On the correlation between the depth of the boundary layer and the columnar aerosol size distribution, Atmos. Environ., 37, 4483-4492, 2003.
Corrigan, C. E., Roberts, G. C., Ramana, M. V., Kim D., and Ramanathan, V.: Capturing vertical profiles of aerosols and black carbon over the Indian Ocean using autonomous unmanned aerial vehicles, Atmos. Chem. Phys., 8, 737-747, 2008, http://www.atmos-chem-phys.net/8/737/2008/.

Di Nicolantonio, W., Cacciari, A., Bolzacchini, E., Ferrero, L., Volta, M., and Pisoni, E.: MODIS aerosol optical properties over north Italy for estimating surface-level $\mathrm{PM}_{2.5}$, Proc. Envisat Symposium 2007, Montreux, Switzerland, 23-27 April 2007 (ESA SP-636, July 2007), http://envisat.esa.int/ envisatsymposium/proceedings/posters/3P5/464392wd.pdf, 2007.

Di Nicolantonio, W., Cacciari, A., Petritoli, A., Carnevale, C., Pisoni, E., Volta, M. L., Stocchi, P., Curci, G., Bolzacchini, E., Ferrero, L., Ananasso, C., and Tomasi, C.: MODIS and OMI satellite observations supporting air quality monitoring, Radiat. Prot. Dosim., 137(3-4), 280-287, 2009.

Doherty, S. J., Anderson, T. L., and Charlson, R. J.: Measurement of the lidar ratio for atmospheric aerosols with a $180^{\circ}$ backscatter nephelometer, Appl. Opt., 38(9), 1823-1832, 1999.

Dubovik, O., Smirnov, A., Holben, B. N., King, M. D., Kaufman, Y. J., Eck, T. F., and Slutsker, I.: Accuracy assessments of aerosol optical properties retrieved from Aerosol Robotic Network (AERONET): Sun and sky radiance measurements, J. Geophys. Res. 105, 9791-9806, 2000.

Engel-Cox, J. A., Hoff, R. M., Rogers, R., Dimmick, F., Rush, A. C., Szykman, J. J., Al-Saadi, J., Chu, D. A., Erica, R. Z.: Integrating lidar and satellite optical depth with ambient monitoring for 3-dimensional particulate characterization, Atmos. Environ., 40, 8056-8067, 2006.

Eresmaa, N., Karpinnen, A., Joffre, S. M., Räsänen, J., and Talvitie, H.: Mixing height determination by ceilometer, Atmos. Chem. Phys., 6, 1485-1493, 2006,

http://www.atmos-chem-phys.net/6/1485/2006/.

Ferrero, L., Bolzacchini, E., Petraccone S., Perrone, M. G., Sangiorgi, G., Lo Porto, C., Lazzati, Z., and Ferrini, B.: Vertical profiles of particulate matter over Milan during winter 2005/2006, Fresen. Envion. Bull., 16(6), 697-700, 2007.

Ferrero, L., Bolzacchini, E., Perrone, M. G., Sangiorgi, G., Lo Porto, C., Ferrini, B. S., Lazzati, Z., and Petraccone, S.: Strumentazione ad ultrasuoni per la caratterizzazione chimica del particolato atmosferico, LAB, Anno XIII, Ottobre 2008, in Italian, 2008.

Fischer, B., Kukkonen, J., Piringer, M., Rotach, M. W., and Schatzmann, M.: Meteorology applied to urban air pollution problems: concepts from COST 715, Atmos. Chem. Phys., 6, 555-564, 2006, http://www.atmos-chem-phys.net/6/555/2006/.

Gobbi, G., Barnaba, F., and Ammanato, L.: The vertical distribution of aerosols, Saharan dust and cirrus clouds in Rome (Italy) in the year 2001, Atmos. Chem. Phys., 4, 351-359, 2004, http://www.atmos-chem-phys.net/4/351/2004/.

Hayasaka, T., Meguro, Y., Sasano, Y., and Takamura, T.: Stratification and size distribution of aerosols from simultaneous measurements with a lidar, a sunphotometer, and an aureolameter. Appl. Optics, 37, 961-970, 1998.

Hinds, W. C.: Aerosol Technology, Wiley-Interscience edition, 1999.

Holtslag, A. A. M., De Bruin, E. I. F., and Pan, H.-L.: A high resolution air mass transformation model for short range weather 
forecasting, Mon. Weather Rev., 118, 1561-1575, 1990.

Holzworth, C. G.: Mixing depths, wind speeds and air pollution potential for selected locations in the United States, J. Appl. Meteorol. 6, 1039-1044, 1967.

IPCC: Climate Change 2007, http://www.ipcc.ch/publications_and_ data/ar4/wg1/en/contents.html, 2007.

Kaufman, Y. J., and Fraser, R. S.: Light Extinction by Aerosols During Summer Air Pollution, J. Appl. Meteorol., 22, 1694-1706, 1983.

Kaufman, Y. J., Tanré, D., and Boucher, O.: A satellite view of aerosols in the climate system, Nature, 419, 215-223, 2002.

Kim, S. W., Yoon, S. C., Won, J. G., and Choi, S. C.: Ground-based remote sensing measurements of aerosol and ozone in an urban area: A case study of mixing height evolution and its effect on ground-level ozone concentrations, Atmos. Environ., 41, 70697081, 2007.

Koren, I., Kaufman, Y. J., Remer, L. A., and Martins, J. V.: Measurments of the effect of amazon smoke on inhibition of cloud formation, Scienze, 303, 1342-1345, 2004.

Kulmala, M., Laakso, L., Lehtinen, K. E. J., Riipinen, I., Dal Maso, M., Anttila, T., Kerminen, V. M., Hõrrak, U., Vana, M., and Tammet, H.: Initial steps of aerosol growth, Atmos. Chem. Phys., 4, 2553-2560, 2004, http://www.atmos-chem-phys.net/4/2553/2004/.

Laakso, L., Grönholm, T., Kulmala, L., Haapanala, S., Hirsikko, A., Lovejoy, E. R., Kazil, J., Kurtén, T., Boy, M., Nilsson, E. D., Sogachev, A., Riipinen, I., Stratmann, F., and Kulmala, M.: Hotair balloon as a platform for boundary layer profile measurements during particle formation, Boreal Environ. Res., 12, 279-294, 2007.

Levy, R. C., Remer, L. A., and Kaufman, Y. J.: Effects of neglecting polarization on the MODIS aerosol retrieval over land, IEEE T. Geosci. Remote Sens., 42(11), 2576-2583, 2004.

Levy, R. C., Remer, L. A., Mattoo, S., Vermote, E. F., and Kaufman, Y. J.: Second generation operational algorithm: Retrieval of aerosol properties over land from inversion of Moderate Resolution Imaging Spectroradiometer spectral reflectance, J. Geophys. Res., 112, D13211, doi:10.1029/2006JD007811, 2007.

Liu, Y., Sarnat, J. A., Kilaru, V., Jacob, D. J., and Koutrakis, P.: Estimating ground-level $\mathrm{PM}_{2.5}$ in the Eastern United States using satellite remote sensing. Environ. Sci. Technol., 39, 3269-3278, 2005.

Liu Y., Franklin M., Kahn R., Koutrakis P.: Using aerosol optical thickness to predict ground-level $\mathrm{PM}_{2.5}$ concentrations in the St. Louis area: A comparison between MISR and MODIS. Remote Sens. Environ., 107, 33-44, 2007.

Maletto A., McKendry, I. G., and Strawbridge, K. B.: Profiles of particulate matter size distributions using a balloon-borne lightweight aerosol spectrometer in the planetary boundary layer, Atmos. Environ., 37, 661-670, 2003.

Matzuki, A., Iwasaka, Y., Shi, G.-Y., Chen, H.-B., Osada, K., Zhang, D., Kido, M., Inomata, Y., Kim, Y.-S., Trochkine, D., Nishita, C., Yamada, M., Nagatani, T., and Nakata, H.: Heterogeneous Sulphate formation on dust surface and its dependence on mineralogy: balloon-borne observations from balloon-borne measurements in the surface atmosphere of Beijing, China. Water Air Soil Poll., 5, 101-132, 2005.

McKendry, I. G. and Lundgren J.: Tropospheric layering of ozone in regions of urbanized comple $\mathrm{x}$ and/or coastal terrain: a review,
Prog. Phys. Geog., 24, 359-384, 2000.

McKendry, I. G., Sturman, A. P., and Vergeiner, J.: Vertical profiles of particulate matter size distributions during winter domestic burning in Christchurch, New Zealand, Atmos. Environ., 38, 4805-4813, 2004.

Menut, L., Flamant, C., Pelon, J., and Flamant, P. H.: Urban boundary-layer height determination from lidar measurements over the Paris area, Appl. Opt., 38, 945-954, 1999.

Morgan, W. T., Allan, J. D., Bower, K. N., Capes, G., Crosier, J., Williams, P. I., and Coe, H.: Vertical distribution of sub-micron aerosol chemical composition from North-Western Europe and the North-East Atlantic, Atmos. Chem. Phys., 9, 5389-5401, 2009, http://www.atmos-chem-phys.net/9/5389/2009/.

Penner, J. E., Andreae, M., Annegarn, H., Barrie, L., Feichter, J., Hegg, D., Jayaraman, A., Leaitch, R., Murphy, D., Nganga, J., and Pitari, G.: Aerosols, their Direct and Indirect Effects, In Climate Change 2001: The Scientific Basis, Cambridge University Press, Cambridge, UK, 291-348, 2001.

Palchetti, L., Bianchini, G., Carli, B., Cortesi, U., and Del Bianco, S.: Measurement of the water vapour vertical profile and of the Earth's outgoing far infrared flux, Atmos. Chem. Phys., 8, 2885 2894, 2008, http://www.atmos-chem-phys.net/8/2885/2008/.

Perrone, M. G., Gualtieri, M., Ferrero, L., Lo Porto, C., Udisti, R., Bolzacchini, E., and Camatini, M.: Seasonal variations in chemical composition and in-vitro biological effects of fine PM from Milan, Chemosphere, 78, 1368-1377, 2010.

Pope, C. and Dockery, D.: Chapter 31. Epidemiology of particle effects, edited by: Holgate, S. T., Koren, H. S., Samet, J. M., and Maynard, R. L., in: Air pollution and health, San Diego, USA, Academic Press, 673-705, 1999.

Raes, F., Van Dingenen, R., Vignati, E., Wilson, J., et al.: Formation and cycling of aerosols in the global troposphere, Atmos. Environ., 34, 4215-4240, 2000.

Rodriguez, S., Van Dingenen, R., Putaud, J. P., Dell'Acqua, A., Pey, J., Querol, X., Alastuey, A., Chenery, S., Ho, K. F., Harrison, R., Tardivo, R., Scarnato, B., and Gemelli, V.: A study on the relationship between mass concentration, chemistry and number size distribution of urban fine aerosol in Milan, Barcelona and London, Atmos. Chem. Phys., 7, 2217-2232, 2007, http://www.atmos-chem-phys.net/7/2217/2007/.

Rojas-Bracho, L., Suh, H., and Koutrakis, P.: Relationships among personal, indoor, and outdoor fine and coarse particle concentrations for individuals with COPD, J. Expo. Anal. Env. Epid., 10(3), 294-306, 2000.

Sarigiannis, D. A., Soulakellis, N. A., and Sifakis, N. I.: Information fusion for computational assessment of air quality and health effects, Photogramm. Eng. Remote Sens., 70(2) 235-245, 2004.

Schneider, J., Hings, S. S., Hock, B. N., Weimer, S., Borrmann, S., Fiebig, M., Petzold, A., Busen, R., and Kärcher, B.: Aircraftbased operation of an aerosol mass spectrometer: Measurements of tropospheric aerosol composition, J. Aerosol Sci., 37, 839857, 2006.

Schwartz, J., Dockery, D., and Neas, L.: Is daily mortality associated specifically with fine particles?, J. Air Waste Manage., 46(10), 927-939, 1996.

Seibert, P, Beyrich, F., Gryning, S. E., Joffre, S., Rasmussen, A., and Tercier, P.: Review and intercomparison of operational methods for the determination of the mixing height, Atmos. Environ., 34, 1001-1027, 2000. 
Seinfeld, J. H. and Pandis, S. N.: Atmospheric chemistry and physics - From air pollution to climate change, WileyInterscience edition, 1998.

Schaap, M., Apituley, A., Timmermans, R. M. A., Koelemeijer, R. B. A., and De Leeuw, G.: Exploring the relation between aerosol optical depth and $\mathrm{PM}_{2.5}$ at Cabauw, The Netherlands, Atmos. Chem. Phys., 9, 909-925, 2009, http://www.atmos-chem-phys.net/9/909/2009/.

Sjogren, S., Gysel, M., Weingartner, E., Alfarra, M. R., Duplissy J., Cozic J., Crosier, J., Coe, H., and Baltensperger, U.: Hygrosopicity of the submicrometer aerosol at the high-alpine site Junfrajoch, $3580 \mathrm{~m}$ a.s.1., Switzerland, Atmos. Chem. Phys., 8, 5715-5729, 2008, http://www.atmos-chem-phys.net/8/5715/2008/.

Spiegelhalter, D. J., Best, N., Carlin, B. P., and Van der Linde, A.: Bayesian measures of model complexity and fit (with discussion), J. R. Stat. Soc., Series B, 64, 583-639 2002.

Spiegelhalter, D., Thomas, A., and Best, N.: WinBugs: Bayesian inference using Gibbs sampler, Manual Version 1.2. Imperial College, London and Medical Research Council Biostatistics Unit, Cambridge, 1998.

Stratmann, F., Siebert, H., Spindler, G., Wehner, B., Althausen, D., Heintzenberg, J., Hellmuth, O., Rinke, R., Schmieder, U., Seidel, C., Tuch, T., Uhrner, U., Wiedensohler, A., Wandinger, U., Wendisch, M., Schell, D., and Stohl, A.: New-particle formation events in a continental boundary layer: first results from the SATURN experiment, Atmos. Chem. Phys., 3, 1445-1459, 2003, http://www.atmos-chem-phys.net/3/1445/2003/.

Taubman, B. F., Hains, J. C., Thompson, A. M., Marufu, L. T., Doddrige, B. G., Stehr, J. W., Piety, C. A., and Dickerson, R. R..: Aircraft vertical profiles of trace gas and aerosol pollution over the mid-Atlantic United States: statistics and meteorological cluster analysis, J. Geophys. Res., 111, D10S07, doi:10.1029/2005JD006196, 2006.
Troen, I. and Mahrt, L.: A simple model of the atmospheric boundary layer model; sensitivity to surface evaporation. Bound.-Lay. Meteorol., 37, 129-148, 1986.

Van Dingenen, R., Raes, F., Putaud, J. P., Baltensperger, U., et al.: A European aerosol phenomenology-1: physical characteristics of particulate matter at kerbside, urban, rural and background sites in Europe, Atmos. Environ., 38, 2561-2577, 2004.

Velasco, E., Márquez, C., Bueno, E., Bernabé, R. M., Sánchez, A., Fentanes, O., Wöhrnschimmel, H., C'ardenas, B., Kamilla, A., Wakamatsu, S., and Molina, L. T.: Vertical distribution of ozone and VOCs in the low boundary layer of Mexico City, Atmos. Chem. Phys., 8, 3061-3079, 2008, http://www.atmos-chem-phys.net/8/3061/2008/.

Vecchi, R., Marcazzan, G., Valli, G., Cerini, M., and Antoniazzi, C.: The role of atmospheric dispersion in the seasonal variation of $\mathrm{PM}_{1}$ and $\mathrm{PM}_{2.5}$ concentration and composition in the urban area of Milan (Italy), Atmos. Environ., 38, 4437-4446, 2004.

Wang, J. and Christofer, S. A.: Intercomparison between satellitederived aerosol optical thickness and $\mathrm{PM}_{2.5}$ mass: Implications for air quality studies, Geophys. Res. Lett., 30(21), 2095, doi:10.1029/2003GL018174, 2003.

Weingartner, E., Burtscher, H., and Baltensperger, U.: Hygroscopic properties of carbon and diesel soot particles, Atmos. Environ., 31(15), 2311-2327, 1997.

Wiegner, M., Emeis, S., Freudenthaler, V., Heese, B., Junkermann, W., Münkel, C., Schäfer, K., Seefeldner, M., and Vogt, S.: Mixing layer height over Munich, Germany: Variability and comparisons of different methodologies, J. Geophys. Res., 111, D13201, doi:10.1029/2005JD006593, 2006.

Wikle, C. K., Berliner, L. M., and Cressie, N.: Hierarchical Bayesian space-time models, Environ. Eco. Stati., 5, 117-154, 1998. 